Cahiers d'études japonaises

$16 \mid 2009$

L'invention des « arts populaires » - Yanagi Sōetsu et le Mingei

\title{
Le discours de Yanagi Sōetsu sur la « peinture populaire » : des peintres révolutionnaires à la révolution picturale
}

'Folk painting' as defined by Yanagi Sōetsu: From revolutionary painters to pictorial revolution

\section{Christophe Marquet}

\section{(2) OpenEdition}

\section{Journals}

\section{Édition électronique}

URL : https://journals.openedition.org/cipango/372

DOI : $10.4000 /$ cipango.372

ISSN : 2260-7706

Éditeur

INALCO

\section{Édition imprimée}

Date de publication : 1 janvier 2009

ISSN : 1164-5857

\section{Référence électronique}

Christophe Marquet, « Le discours de Yanagi Sōetsu sur la « peinture populaire » : des peintres révolutionnaires à la révolution picturale », Cipango [En ligne], 16 | 2009, mis en ligne le 15 novembre 2011, consulté le 30 juin 2021. URL : http://journals.openedition.org/cipango/372 ; DOI : https:// doi.org/10.4000/cipango.372

Ce document a été généré automatiquement le 30 juin 2021.

\section{(ब) $(1) \Theta$}

Cipango est mis à disposition selon les termes de la Licence Creative Commons Attribution - Pas d'Utilisation Commerciale 4.0 International. 


\title{
Le discours de Yanagi Sōetsu sur la " peinture populaire »: des peintres révolutionnaires à la révolution picturale
}

\author{
'Folk painting' as defined by Yanagi Sōetsu: From revolutionary painters to \\ pictorial revolution
}

Christophe Marquet

Nous tenons à remercier le Mingeikan de Tōkyō, et en particulier $M^{m e}$ Utsumi Teiko et M. Ogyū Shinzō, ainsi que le Musée Serizawa de Shizuoka, de nous avoir autorisés gracieusement à reproduire les œuvres présentées dans cet article.

Il faut une révolution du concept de peinture. 絵画の概念には一革命がなければならない。

Yanagi Sōetsu, Essai sur la peinture, 1934

1 L'exposition «L'esprit mingei au Japon » du Musée du quai Branly, centrée sur l'objet artisanal et le mobilier, n'a accordé qu'une place limitée, voire anecdotique, à la

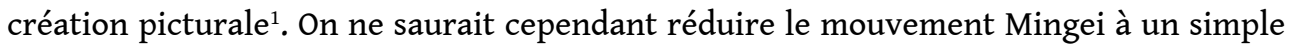
renouveau de l'artisanat ou à un creuset du design moderne. Dans le domaine pictural également, la contribution de son fondateur, Yanagi Sōetsu, fut essentielle. Cette importance se mesure moins au nombre d'œuvres picturales laissées par les artistes liés à ce mouvement, qui compta peu de peintres, que par la redécouverte - ou la réhabilitation - par Yanagi de tout un pan ignoré, voire méprisé de l'art d'Edo, celui de la « peinture populaire».

2 C'est de cet aspect essentiel du Mingei que nous souhaitons traiter, en examinant l'approche par Yanagi de certaines formes picturales populaires en Corée et au Japon, et le discours qu'il élabora en se fondant sur ces œuvres, pour appeler à révolutionner le concept même de peinture. 


\section{La découverte de la peinture populaire coréenne}

3 On observe, vers la fin des années 1910, un basculement du centre d'intérêt de Yanagi, qui passe de l'art occidental moderne à celui de l'Asie orientale et, du même coup, du culte de l'expression individuelle à des formes de peintures anonymes et populaires issues de traditions coréennes et japonaises. On pourrait être surpris de ce bouleversement radical du discours de Yanagi, lui qui à peine quelques années plus tôt faisait l'éloge, avec ses jeunes compagnons de la revue Shirakaba, d'artistes qui « révolutionnèrent » la création picturale en Occident, comme Van Gogh, Gauguin ou Matisse, car ils symbolisaient à ses yeux cette symbiose entre quête de l'originalité, expression individuelle et destin personnel ${ }^{2}$. Mais d'une certaine manière, on pourrait considérer que Yanagi ne fait que transposer sur des œuvres populaires orientales le même enthousiasme pour une forme de primitivisme qui l'avait fasciné à la découverte des peintres postimpressionnistes.

Parmi les facteurs de cette mutation du regard et du discours de Yanagi se trouvent notamment les voyages qu'il entreprend à partir de 1916 dans la Corée récemment colonisée, à l'incitation d'Asakawa Noritaka 浅川伯教 (1884-1964), un jeune instituteur installé à Séoul, qui se destinait à devenir sculpteur et qu'une passion commune pour Rodin l'avait conduit à rencontrer deux ans plus tôt. Ce dernier lui fait d'abord découvrir la céramique populaire coréenne et en particulier la porcelaine blanche de la dynastie Yi utilisée au quotidien. Dès 1921, Yanagi est en mesure d'organiser dans une petite galerie du quartier de Kanda à Tōkyō une première exposition d'art coréen, usant à dessein de l'expression minzoku bijutsu 民族美術 (accompagnée de sa version anglaise Folk Art) pour désigner toute une catégorie d'œuvres « populaires » jusqu'alors négligées ${ }^{3}$.

Yanagi Sōetsu, 1921

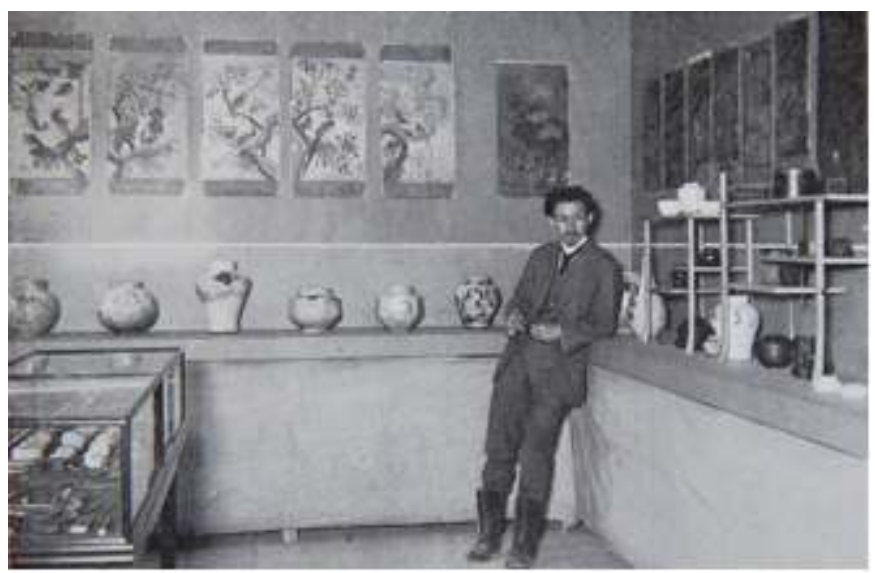

yANAgI Sōetsu À L'EXPosition d'ART POPULAIRE CORÉEn ORgANISÉE En 1921 À LA gaLerie RUISSō À KANDA (TŌKYō).

Elle comprend, à côté d'une majorité de céramiques, des peintures de la fin de la période Chosŏn (1392-1910) qui furent pour lui une révélation, en ce sens qu'il y découvrit une forme de modernité non occidentale et non individuelle. "Le temps viendra, pour nous qui sommes familiers avec les arts d'Occident, de reconsidérer les arts de cet Orient qui est notre terre natale", déclare-t-il à l'occasion de cette exposition, en réunissant la Corée et le Japon dans un même creuset ${ }^{4}$. 
6 Yanagi lance conjointement, avec Asakawa, le projet d'un Musée des arts populaires coréens (Chōsen minzoku bijutsukan 朝鮮民族美術館), afin de faire découvrir la valeur des objets des siècles récents " liés à la vie du peuple » et d'en étudier l'histoire, mais aussi dans le but de promouvoir la création d'un nouvel «art manuel » (shugei 手藝) oriental, déplorant que sous l'influence de la civilisation matérielle occidentale celui-ci soit en voie de disparition ${ }^{5}$. L'esprit du mouvement qu'il baptisera bientôt du nom de Mingei est donc ici en gestation: il combine le travail de sauvegarde et la création d'œuvres nouvelles. Ce musée ouvrira trois ans plus tard à Séoul, dans deux pavillons de l'ancien palais royal de Gyeongbok 景福宮 qu'il avait contribué à sauver de la destruction en s'opposant au projet des autorités japonaises ${ }^{6}$. C'est à travers ce combat pour la défense et la reconnaissance de l'art populaire coréen que s'est opérée la prise de conscience chez Yanagi d'une autre voie possible dans la création picturale.

Musée des arts populaires coréens

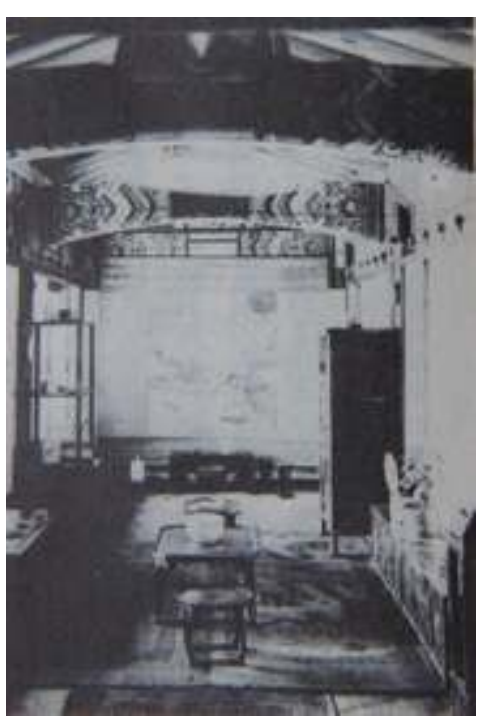

LE MUSÉE des ARTS POPULAIRES CORÉENS FONDÉ EN 1924 dANS L'ANCIEN PALAIS ROYAL DE SÉOUL.

7 Bien que sa découverte de la peinture populaire coréenne date de cette fin des années 1910, Yanagi n'écrira que tardivement à son propos, dans trois textes publiés dans les dernières années sa vie, en 1957 et en 1959, notamment dans un numéro spécial consacré à ce sujet par la revue Mingei ${ }^{7}$.

8 Le premier de ces textes lui fut inspiré par la découverte d'une œuvre sur paravent appartenant à un genre appelé óhaedo 魚蟹圖, ou “ peinture de poissons et de crabes " ${ }^{8}$, qui symbolise la prospérité, la fécondité et l'harmonie familiale, et que l'on destinait pour cette raison à la chambre de l'épouse ou à celle des jeunes mariés. 


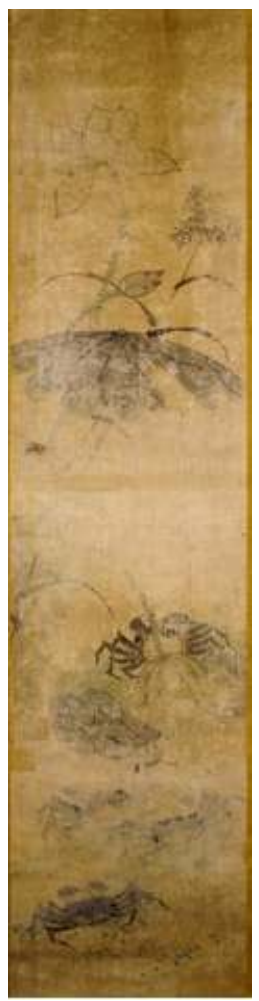

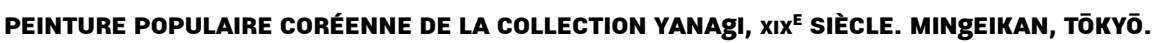

Devant la facture plutôt maladroite et la composition fantaisiste de cette œuvre anonyme du milieu de l'époque Chosŏn - exécutée par un de ces peintres itinérants qui passaient de village en village -, Yanagi perçoit une sorte de nonchalance, étrangère à tout souci de réalisme. Ce type d'œuvre rend inopérants les critères habituels appliqués à la peinture moderne, comme le génie individuel ou l'habileté technique. En contemplant cette peinture, Yanagi évoque d'ailleurs l'ennui que lui inspire désormais un art moderne fondé sur des discours et des théories esthétiques et motivé par une quête incessante de la nouveauté. Il découvre la possibilité d'une "autre voie » qui renoue à ses yeux avec un enseignement du Sūtra du cœur de sagesse (Hannya shinkyō 般 若心経) : «N'avoir point d'attachement, c'est n'avoir plus de crainte » (keige naki ga yue $n i$ kufu aru koto nashi 無罣礙故無有恐怖).

10 Mais pour Yanagi, cette peinture coréenne issue de croyances populaires n'a pas seulement la vertu du détachement et de l'apaisement. En cette fin des années 1950, marquée par le triomphe de l'art abstrait, il y découvre une autre forme de modernité, capable de concurrencer celle des créateurs contemporains ${ }^{9}$ :

De notre point de vue, cette peinture recèle une grande beauté. Elle est d'une originalité infinie, au point qu'on n'en trouve d'exemple dans aucun autre pays. Supposons qu'un artiste capable de réaliser à lui seul tous ces types d'œuvres naisse aujourd'hui, il ne fait aucun doute qu'il serait acclamé et deviendrait même la célébrité de son temps. En tous les cas, il serait apprécié comme un créateur original. Avec une telle nouveauté, à notre époque où le dépassement du réalisme et le caractère abstrait sont l'objet de toutes les attentions, ne serait-il pas remarqué entre tous au point de faire école?

処が今日の吾々から見ると、とても美しい所がある。極めて独創的で、一寸 他国にその例を見埕の絵である。仮りにこんな絵を一人で種々と描く画家が 今輩出したら、さぞや喝采を博して、著名な一世の画家とまで成るであらう。 
兔に角大した独創的作家といふ評判をかち得るに違ひない。大いに新しさがあ るのであつて、此頃ではさしづめその超写実的な所や、抽象的性質が注目され

て、鮮かに一派を創る画家とさへ目されるのではあるまいか。

11 Pour Yanagi, la peinture coréenne mérite d'être étudiée non seulement pour son histoire, mais aussi pour ce qu'elle peut enseigner aux artistes contemporains, qui y trouveront une source d'étonnement, car elle combine à la fois «modernité » et « liberté ».

12 L'un des principaux mérites du travail de Yanagi sur la peinture populaire coréenne un domaine qui n'avait jusqu'alors pour ainsi dire pas attiré l'attention des collectionneurs, des musées ou des historiens d'art - a été de proposer pour la première fois une classification thématique des œuvres et d'en expliquer les caractéristiques ${ }^{10}$. Il a ainsi pu établir une typologie en cinq catégories, chaque type d'œuvre ayant une fonction et un usage particuliers :

- les peintures composées de caractères d'écriture ornementés (moji-e 文字絵) qui expliquent visuellement le sens d'idéogrammes à connotation morale ;

- les peintures auspicieuses (kikkyō ni chinamu mono 吉|凶| に因むもの), comme la représentation du tigre protecteur des quatre orients ;

- les peintures à motifs traditionnels (dentō-teki gadai no mono 伝統的画題のもの);

- les natures mortes (seibutsu-ga 静物画), dont principalement les œuvres sur le thème des objets du lettré ;

- les peintures qui s'inspirent des trois enseignements que sont le confucianisme, le bouddhisme et le taoïsme (ju, butsu, dō no sankyō ni hassuru mono 儒、仏、道の三教に発する もの).

\section{Le tigre et ses petits}

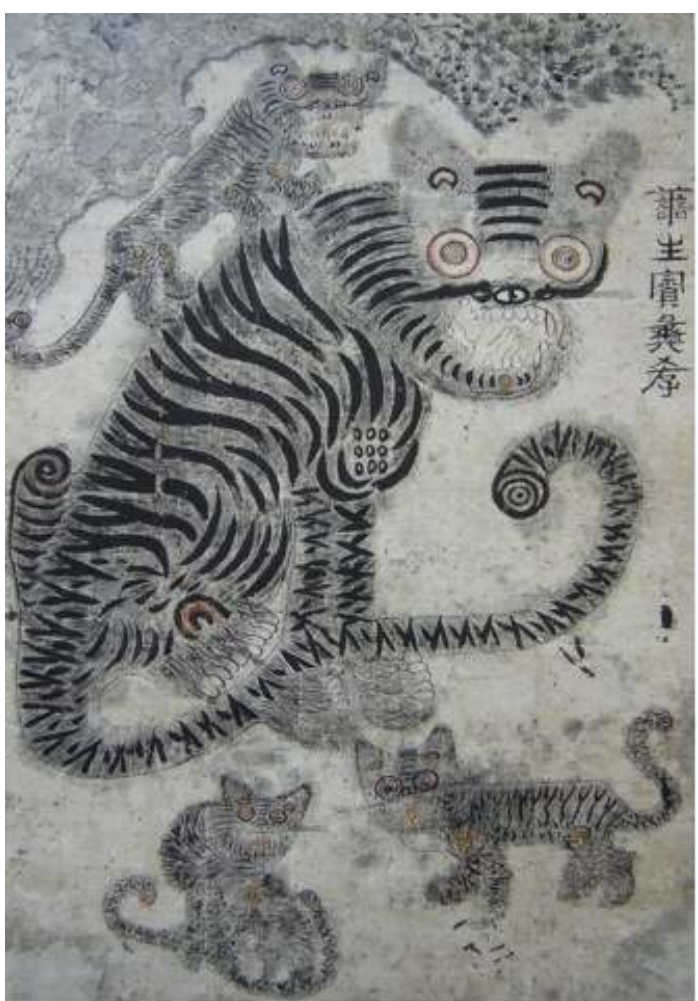

PEINTURE POPULAIRE CORÉENNE DE LA COLLECTION SERIZAWA, XIXE SIÈCLE. MUSÉE SERIZAWA, SHIZUOKA. 
Paravent aux objets du lettré (détail)

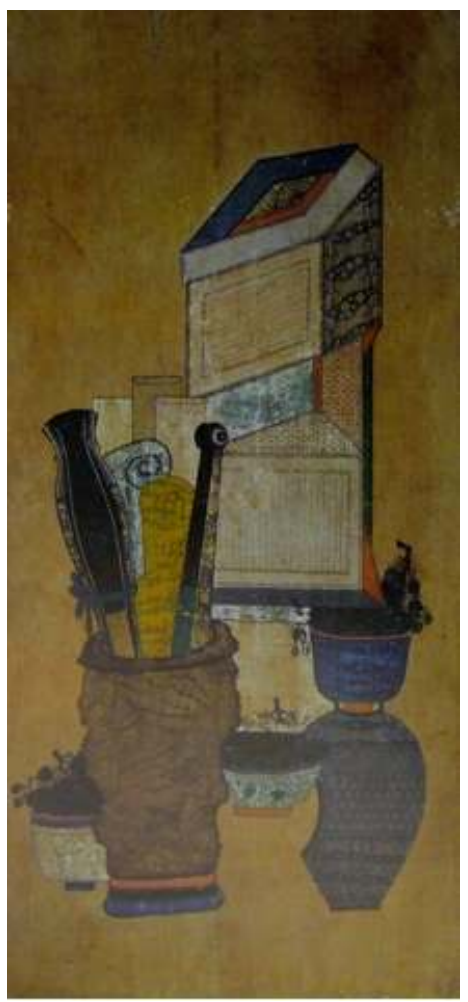

PEINTURE POPULAiRe CORÉENNE de LA COLlection YANAgI. MingeiKan, TōKYō.

Cette approche de la peinture populaire coréenne fut particulièrement pionnière quand on sait que l'intérêt pour cet art, en Corée même, ne se manifestera qu'à partir des années 1960, dans le prolongement des travaux de Yanagi, notamment grâce aux recherches de Cho Cha-yong 趙子庸 (1926-2000), le père des études sur l'art populaire coréen ${ }^{11}$. Le terme minga (en coréen minhwa), "peinture populaire ", y sera d'ailleurs adopté pour désigner ce genre qui n'était jusqu'alors regardé que comme une forme mineure d'art «non orthodoxe». Dans un premier temps, les chercheurs coréens situeront leurs travaux dans le cadre du paradigme forgé par Yanagi d'un art populaire à la fois «national » - c'est-à-dire étranger à l'influence chinoise et témoignant des modes de vie, de pensée et des croyances du peuple coréen - et «moderniste », en ce sens que son primitivisme plastique fut interprété par certains comme une source de l'art moderne ${ }^{12}$.

14 En 2005, une exposition de peintures coréennes populaires d'une ampleur inédite, constituée de cent vingt pièces provenant des collections japonaises, fut organisée pour la première fois dans une institution publique en Corée, au Musée d'histoire de la ville de Séoul, grâce à la collaboration du Nihon mingeikan, le musée fondé par Yanagi ${ }^{13}$. Cette exposition fut conçue comme un hommage à Yanagi Sōetsu, dont les recherches et le discours de défense des arts populaires coréens permirent de préserver des exemples significatifs de ces peintures. Elle fut aussi l'occasion de présenter les nouvelles interprétations du concept de "peinture populaire» par les chercheurs coréens ${ }^{14}$. 


\title{
Les peintures d'Ōtsu : un art du peuple entre dévotion, satire et morale
}

À partir de la fin des années 1910, parallèlement aux peintures coréennes, Yanagi découvre les peintures japonaises d'Ōtsu ${ }^{15}$, ainsi que différentes formes de productions graphiques populaires, qui vont des rouleaux enluminés anonymes de style naiif ${ }^{16}$ aux illustrations gravées des incunables du début de l'époque d'Edo, en passant par les peintures sur verre et les estampes bouddhiques ${ }^{17}$.

Le rouleau du conte de l'île artificielle

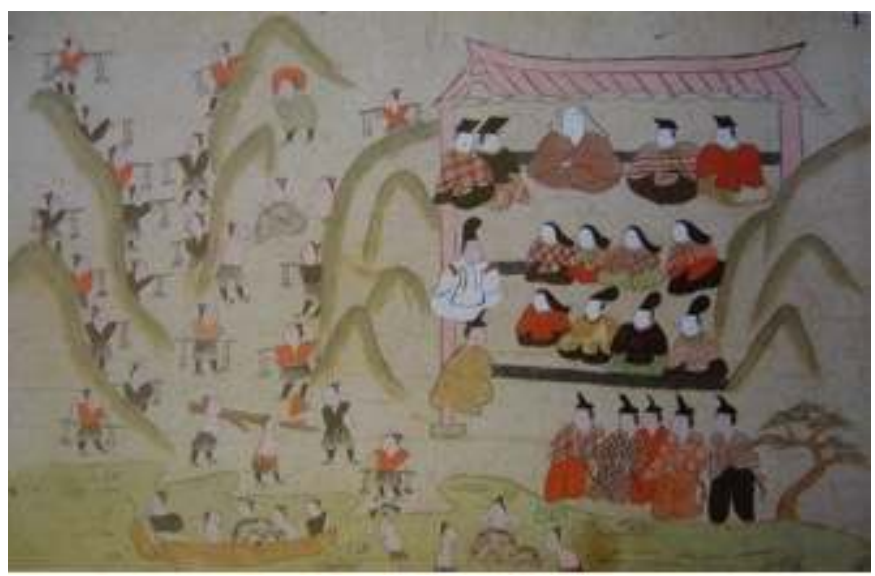

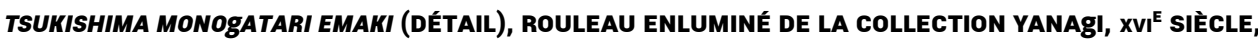
PRÉSENTÉ dans La ReVUe Kōgeı EN 1936. MingeIKaN, TōKYō.

Peu à peu, il forge le concept générique de "peinture populaire " pour les réunir et crée le néologisme minga 民畫, auquel il donnera parfois les équivalents de peasant painting ou de folk painting. Ce terme, qui connaîtra une fortune considérable, apparaît pour la première fois sous sa plume en 1927, dans un ouvrage où il évoque des peintures rustiques de l'époque d'Edo ${ }^{18}$ :

\begin{abstract}
Les images qui n'ont pas été conçues comme des peintures indépendantes les unes des autres, mais qui sont produites en grand nombre pour un usage concret par le peuple, comme souvenir ou comme offrande aux divinités, je leur donne le nom de "peintures populaires». Ce sont par exemple les " peintures d'ōtsu » ou les " plaquettes votives»; les "peintures à la gouache » sont aussi de bons exemples de peintures populaires. Comme elles proviennent $d u$ peuple, ces peintures sont "rustiques». Ces images furent exécutées en grande quantité à l'intention des gens ordinaires, par des artisans anonymes.

単独に一枚々々絵画として出来たものではなく、民間で土産ものとか、奉納 品とか実際につかう為、沢山製産された画を、私は「民画」と名づける。例 へば「大津絵」とか「絵馬」とかの類であつて、「泥絵」も民画のよき一例に なる。民間のもの故、云はぶ「下手」な画である。一般民衆の為に、無名の 画工が沢山画いた絵である。
\end{abstract}

Les idées maîtresses de Yanagi sur la peinture populaire sont déjà présentes dans ce texte. Il les développera à partir de la fin des années 1920 et au cours des années 1930 en étudiant principalement les trois genres de l'époque d'Edo évoqués ici : les peintures d'ōtsu (Ōtsu-e), les plaquettes votives $(\mathrm{ema})^{19}$ et les peintures paysagères à la gouache (doro-e). Dès 1929, il organisera à Kyōto, essentiellement à partir de sa propre collection, une exposition d'art populaire comportant ces trois types d'œuvres, réunies sous le terme de minga ${ }^{20}$. 
Yanagi s'attelle à la rédaction d'un livre majeur sur le sujet, Shoki Ōtsu-e 初期大津繪 (Les débuts de la peinture d'Ōtsu), qui sera publié en avril 1929 dans une collection lancée par la Maison des arts populaires alors en cours de création ${ }^{22}$. Sorte de "musée imaginaire » de la peinture populaire, cet ouvrage reste aujourd'hui encore une référence incontournable pour l'étude de ce genre et la compréhension de ses thèmes. Il a surtout mis en lumière, à une période où ces images n'intéressaient guère le milieu académique $^{23}$, tout un pan de la création picturale populaire de l'époque d'Edo.

\section{Les débuts de la peinture d'Ōtsu}

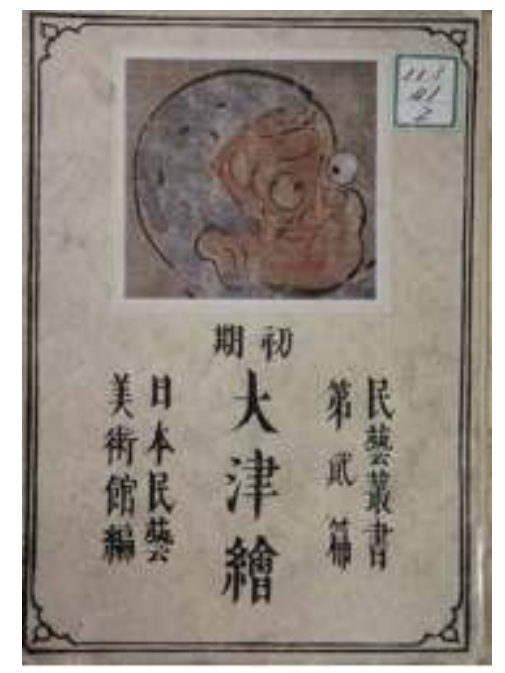

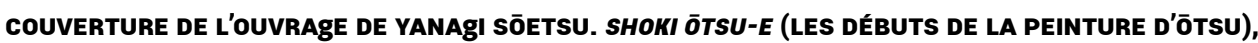
1929. 
Une première initiative avait été lancée en 1926, avec l'organisation d'une exposition de ce genre de peinture à ōtsu même et la publication d'un important catalogue reproduisant plus de cent quarante pièces ${ }^{24}$. Dans la préface de cet ouvrage, le peintre Yamamura Kōka 山村耕花 (1886-1942) militait déjà, comme Yanagi allait bientôt le faire à son tour, pour la reconnaissance de ces peintures négligées par l'histoire de l'art, dont le caractère populaire et la modestie lui semblaient les premières qualités :

Les « peintures d'ōtsu » n'ont rien de cet aspect aristocratique qui marque encore les ukiyo-e de la même époque. Ce sont des œuvres totalement populaires. Leur qualité réside dans cette dimension populaire. Dans les "peintures d'ōtsu» on ne retrouve pas cet orgueil qu'ont toujours possédé les artistes à toutes les époques et qui les pousse à créer pour la postérité. Cette absence de volonté de plaire est louable. Les « peintures d'ōtsu» ne cherchent pas à se faire valoir et c'est là une chose que ne pourra jamais surmonter aucun grand artiste. Cette absence d'ostentation est appréciable.

『大津絵』には、当時の浮世絵にはまだ遣つてみたところの、貴族臭がない。 完全に庶民のものになりきつてみる。其民衆的なところがい、『大津絵』に は、如何なる时代の藝術家も必ず意識するところの、自己の芸術を後世に向京 自負がない。其匠気のないところがい、『大津絵』には、如何なる大藝術家 も遂に超越することの出来ない、これ見よといふ意識がない。其街気のないと ころがい、

Yanagi avait prêté à cette exposition une dizaine d'œuvres de sa collection personnelle, alors en cours de constitution, mais il considéra avec un regard critique le caractère hétéroclite du choix des pièces retenues et, sans doute aussi, leur absence de mise en perspective historique.

\section{Le singe portant une cloche et une lanterne}

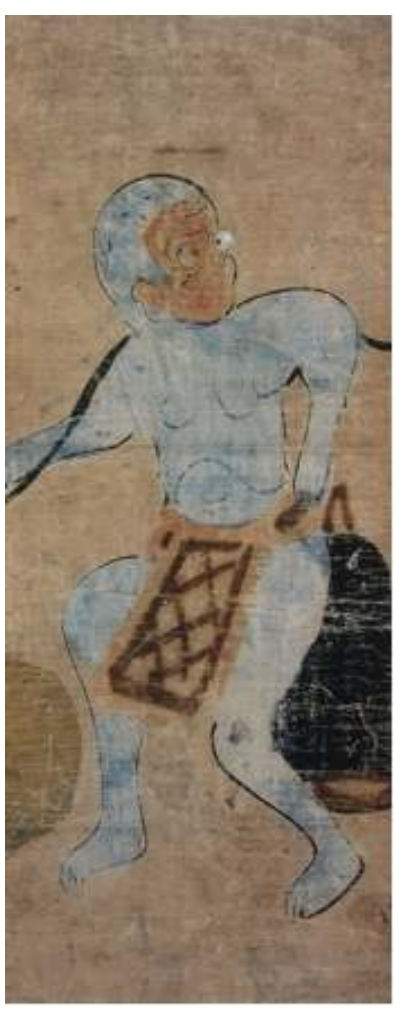

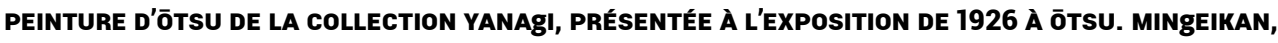
TŌKYō. CETTE œUVRE A APPARTENU À L'ORIgINE AU PEINTRE ASAI CHŪ. 

afin d'établir une chronologie et une histoire fondée sur des documents. Yanagi a voulu par ces recherches philologiques inscrire dans l'histoire de l'art cette peinture anonyme autour de laquelle gravitaient de nombreuses légendes forgées dès l'époque d'Edo, notamment par un homme de théâtre comme Chikamatsu. Sa motivation était aussi de comprendre l'origine de ce genre pictural, qui était encore largement incertaine. De ce fait, cette compilation de sources occupe une partie importante de son ouvrage. Elle est accompagnée de plusieurs documents visuels particulièrement éclairants, empruntés à des livres illustrés de l'époque d'Edo, comme cette remarquable vue de l'échoppe d'un peintre d'ōtsu provenant du Guide des sites célèbres de la route du Tōkaidōo (Tōkaidō meisho zue 東海道名所図会) de 1797.

\section{Échoppe d'un peintre à Ōtsu}

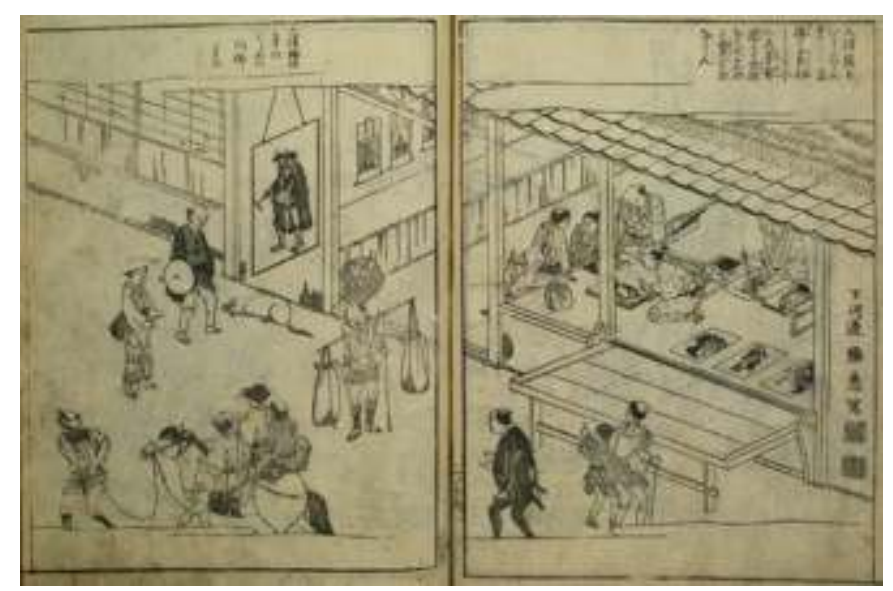

D'APRÈs Le GUIDE des SITES CÉlÈbres de LA ROUTE dU TōKAIDō (TōKAIDō MEISHO ZUE), 1797.

L'autre travail essentiel de Yanagi a consisté à établir une typologie de ces peintures, c'est-à-dire concrètement à en définir les «sujets canoniques » (gadai 画題) et à en analyser l'évolution. Cette description minutieuse, fruit d'un travail considérable d'observation des œuvres et d'examen des sources écrites (car pour certains sujets aucune œuvre n'est conservée), lui a permis d'établir une liste de plus d'une centaine de thèmes typiques ${ }^{26}$.

Cette compilation n'aurait pas été possible sans un travail préliminaire consistant à réunir les œuvres elles-mêmes. Yanagi a permis ainsi de sauver de l'oubli ces peintures et de constituer pour la Maison des arts populaires une collection qui est aujourd'hui, avec environ cent quarante pièces ${ }^{27}$, de loin la plus importante au Japon ${ }^{28}$. Quand on pense que, selon certaines estimations, ce sont plusieurs millions de ces images qui furent produites au cours des deux siècles et demi de l'époque d'Edo, on mesure néanmoins combien il ne s'agit que d'un infime échantillon, la majorité des peintures ayant disparu ${ }^{29}$.

Enfin, la contribution essentielle de Yanagi revient à son analyse de l'évolution du sens et de la fonction de ces peintures au cours de l'époque d'Edo. Il établit une périodisation 
en quatre phases, montrant que les images d'ōtsu furent d'abord des œuvres à caractère et à fonction religieux, qu'elles prirent ensuite un sens satirique, avant de devenir des supports pour la diffusion de principes moraux, en lien avec le développement dans la seconde moitié $\mathrm{du}$ xvIII ${ }^{\mathrm{e}}$ siècle d'un courant éducatif populaire d'inspiration confucianiste appelé shingaku 心学 («discipline [pour le développement] intérieur »). La dernière phase correspond à l'usage de ces images comme simple talisman et s'achève avec l'arrêt de leur production à la fin du XIX ${ }^{e}$ siècle, suite au développement des transports modernes qui fit perdre à Ōtsu son statut de ville relais.

Malgré une tentative de remise en cause de l'antériorité des Ōtsu-e à thème bouddhique sur les peintures à thème profane, par l'historien de l'estampe Nakada Katsunosuke dans les années $1940^{30}$, la périodisation proposée par Yanagi est toujours en usage. Elle a permis de mettre en ordre le corpus des images d'ōtsu et de révéler leur rôle social. De ce point de vue, Yanagi a contribué à donner à ces peintures une nouvelle valeur et une nouvelle identité, alors que depuis le début du xix siècle on ne leur attribuait plus qu'un sens talismanique et que leurs sujets s'étaient réduits à une dizaine de motifs.

Pour comprendre le sens satirique de ces images et leur utilisation à des fins éducatives, Yanagi a notamment recensé la plupart des «poèmes moraux » (dōka 道歌) - quelque cent quarante en tout - que l'on trouve sur les œuvres produites au cours du XVIII $^{\mathrm{e}}$ siècle $^{31}$.

\section{Peinture d'ōtsu au chat et à la souris}

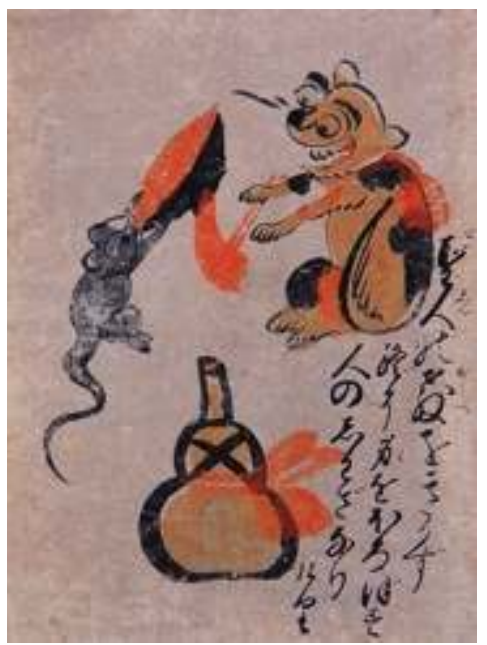

COMPORTE LA SENTENCE MORALE : « NE POINT ÉCOUTER L'ENSEIgNEMENT DES SAINTS EST UN ACTE QUI CONDUIT L'HOMME À SA PERTE ॥ (SEIJIN NO OSHIE O KAKAZU TSUI NI MI O HOROBOSU HITO NO SHIWAZA NARI KERI). ANCIENNE COLLECTION KOMENAMI SHŌICHI, MINgEIKAN, TŌKYŌ.

L'étude de ces inscriptions lui a permis d'interpréter le sens de certaines images qui était jusqu'alors resté obscur et aussi de comprendre que des significations multiples avaient parfois été données à un même sujet, conférant une complexité insoupçonnée à cette imagerie.

31 En conclusion, les Ōtsu-e, pour Yanagi, à la différence des autres formes de peinture populaire de l'époque d'Edo, ne sont pas simplement descriptives, mais elles sont «l'expression du sentiment intérieur » (kokoro no hyōgen) de la classe populaire ${ }^{32}$. En ce sens, il ne s'agit pas d'une peinture " primitive ", mais d'un témoignage de la "sagacité du peuple» (minshū no kichi). Il affirme ainsi que « ces peintures allégoriques remplies 
d'humour étaient sans doute le seul moyen laissé au peuple à cette époque pour critiquer la société ». On retrouve ici un point de vue souvent exprimé à cette période, notamment par l'écrivain Nagai Kafū 永井荷風 qui voyait dans les arts d'Edo, et en particulier dans l'ukiyo-e, une forme de résistance populaire par la veine du divertissement ${ }^{33}$. Pour Yanagi aussi cette époque d'Edo se caractérise par l'appropriation de l'art par le peuple, phénomène qui ne s'observe pas aux époques antérieures.

Enfin, au-delà de cette étude historique des peintures d'ōtsu et du catalogage de leurs sujets, Yanagi a défendu à travers cette forme d'imagerie populaire une autre voie possible pour la création picturale, fondée - comme il s'en explique dans un chapitre de son livre de 1929 intitulé « L'esthétique et la nature des images d'ōtsu » (Ōtsu-e no bi to sono seishitsu) - sur la "répétition " de sujets "déterminés " afin de "produire des œuvres en quantité ». Ces trois éléments s'opposent radicalement à la conception de la création artistique qui a cours en Occident depuis l'apparition de l'artiste au sens moderne au cours du XviII ${ }^{e}$ siècle, fondée sur la singularité, l'innovation, le caractère unique de l'œuvre et sur l'idée de la vocation individuelle par opposition au travail professionnel ${ }^{34}$. Yanagi, en s'appuyant notamment sur les idées de William Morris et du mouvement Arts and Crafts qui visait à réhabiliter le travail artisanal dans l'Angleterre victorienne, entend surmonter cette image romantique de l'artiste pour qui le beau s'oppose à l'utile, l'imagination personnelle au métier manuel ${ }^{35}$. Il cherche au contraire dans l'art d'Edo des exemples de genres où le créateur s'efface derrière son œuvre, dans l'esprit de ce qu'il nommera, en se référant au vocabulaire bouddhique, le tariki 他力, la "force exogène» c'est-à-dire l'attitude qui consiste à s'en remettre au pouvoir salvateur d'Amida et non pas à recourir à ses « propres forces » (jiriki 自力) par l'ascèse individuelle.

33 Yanagi tenta dès cette époque de faire connaître en Europe et aux États-Unis ses travaux sur la peinture et l'art populaires, afin de diffuser à l'étranger une autre image de l'art japonais que celle qui avait cours depuis la mode du japonisme à la fin du XIX siècle. Il déplorait que l'on y apprécie surtout l'estampe ukiyo-e et ses grands maitres, alors que les Ōtsu-e, qui datent de la même époque, étaient négligées ${ }^{36}$. En avril 1929, le mois même de la publication de son livre sur les peintures d'ōtsu, il partit pour l'Europe, visitant l'Angleterre, la France ou encore la Suède, où il fut particulièrement intéressé par le Nordiska Museum de Stockholm, l'une des premières institutions consacrées aux traditions populaires, fondé en 1873. Cet exemple l'encouragea à mener à bien son propre projet de musée.

Yanagi gagna ensuite les États-Unis, où il était invité à enseigner l'histoire de l'art japonais à l'Université de Harvard ${ }^{37}$. Il y donna une série de cours sur les « idéaux du bouddhisme du Grand Véhicule dans l'art », les « critères du Beau au Japon, à travers la cérémonie du thé $»^{38}$ ou encore la " beauté de l'art populaire ». Il y assista également le professeur Langdon Warner (1881-1955), conservateur du département d'art oriental du Fogg Art Museum de Cambridge (Mass.), dans ses travaux sur la statuaire bouddhique japonaise, et son épouse, Lorraine d'Orémieulx Warner, dans ses recherches sur la céramique coréenne ${ }^{39}$. Warner avait des liens anciens avec le Japon, pour y avoir étudié l'histoire de la sculpture sous la direction d'Okakura Tenshin dès les années 1907-1908. Sa rencontre avec Yanagi, qui remontait à une mission d'étude en Corée en 1928, le conduisit à élargir son regard sur l'art japonais, en y introduisant ses composantes populaires. En témoignent plusieurs de ses ouvrages dans lesquels il 
évoque avec enthousiasme les œuvres du «moine paysan » Mokujiki ${ }^{40}$ ou les peintures d'ōtsu face auxquelles « the foreigner is not blinded by the flash of a master's signed name or by any dexterity $»^{41}$.

Pendant ce séjour, Yanagi s'efforça de faire découvrir au public américain cet art encore inconnu des peintures d'ōtsu. Il donna tout d'abord une conférence sur le sujet en décembre 1929. Puis, grâce à Warner, il publia, dans la revue Eastern Art, en se fondant sur son récent ouvrage, un long article sur le sujet, richement illustré d'une quarantaine de planches, qui constitua la première et pendant longtemps l'unique présentation circonstanciée de ce genre en Occident ${ }^{42}$. Yanagi organisa parallèlement en avril-mai 1930, au Fogg Art Museum, une exposition d'une cinquantaine de peintures d'Ōtsu à partir notamment des œuvres de sa propre collection ${ }^{43}$.

Le singe immobilisant le poisson-chat avec une calebasse

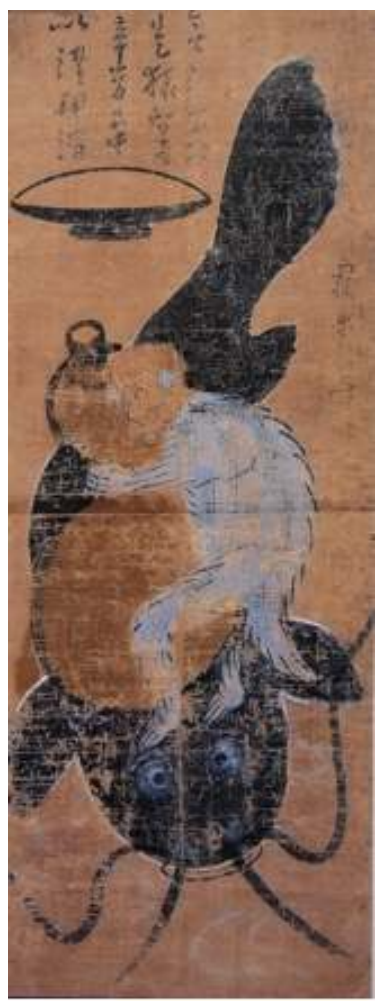

PEINTURE d'ōtsu de LA COLL. yANAgI, PRÉSENTÉE À L'EXPOSITION « JAPANESE PEASANT PAINTINg », FOgg ART MUSEUM, 1930. MINgEIKAN, TŌKYō. 


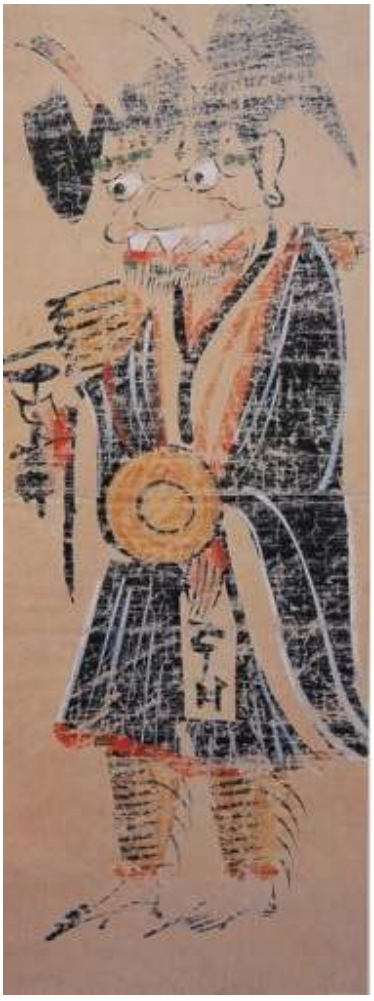

PEINTURE d'ōTSU de LA COLLECTION yANAgI, PRÉSENTÉE À L'EXPOSITION « JAPANESE PEASANT PAINTINg ", FOgg ART MUSEUM, 1930. MINgEIKAN, TŌKYō.

Dans l'introduction de son article, intitulé "The Peasant Paintings of Ōtsu, Japan », Yanagi posa les bases d'une réflexion théorique sur la nature particulière de ce genre de peinture et sur la transformation des critères de jugement qu'elle nécessite pour être appréciée. On pourrait résumer sa conception par les couples de termes antagonistes qu'il utilise pour caractériser cet art populaire par opposition à la peinture considérée comme un des beaux-arts: folk art / fine art; artisan / artist; unsigned / individuality; common thing / self expression; spontaneous picture / aesthetic ideas ; picture to be used / picture to be exhibited ; sweat / caprice. Yanagi explique en outre que si une telle définition est de nature à jeter le trouble parmi ses lecteurs occidentaux baignés dans une "ère individualiste ", la cause en revient à l'évolution du rapport à l'art dans l'Occident moderne depuis la Renaissance :

[...] it seems to me that, since the time of the Renaissance in the West, people have lost something of the right notion of beauty that is ordinary and have stopped making common things beautifully.

37 Yanagi partage ici avec Ruskin ou William Morris, qui influencèrent sa vision, une manière d'idéaliser le Moyen Âge comme une période où l'objet artisanal était synonyme de beauté.

Ce discours sur la peinture populaire, Yanagi va le poursuivre et en accentuer le caractère de plaidoyer pour un retour à la conception « médiévale » de l'art, à travers une série de textes publiés au cours des années 1930, notamment sur un autre genre de peinture populaire de l'époque d'Edo, les doro-e. 


\section{Les gouaches paysagères de la fin d'Edo : plaidoyer pour une révolution picturale}

En 1931, Yanagi publie tout d'abord dans la revue Kōgei 工藝 (Artisanat), qu'il vient de fonder pour faire connaitre les idées et les collections des partisans de son mouvement, des commentaires à propos d'une série de six peintures réunies par lui-même et ses amis, dont l'artiste teinturier Serizawa Keisuke 芹沢銈介. Ces œuvres relèvent de genres différents (Ōtsu-e, plaquettes votives, doro-e), mais elles ont en commun de correspondre à sa définition de la "peinture populaire » ${ }^{44}$. Le début de ce texte se présente comme un plaidoyer pour leur reconnaissance :

Nous sommes fascinés par la beauté des peintures populaires. Ce que nous entendons par là, ce sont des peintures anonymes, nées au sein même du peuple. Ce genre de peinture a généralement été déconsidéré. Notre époque moderne ne jurant que par l'originalité, il est logique que ce genre de peinture banale ait été relégué au dernier rang et que sa valeur ne soit pas reconnue. Ces peintures n'ont servi qu'à satisfaire la passion des dilettantes et, de nos jours, beaucoup de peintres les regardent encore avec mépris. Mais je pense qu'à l'avenir elles seront reconsidérées et que viendra le temps où leur valeur sera reconnue tout naturellement.

吾々は民画の美にいたく心を引かれてるる。民画と云ふのは民衆の間から生れ る無銘の絵画を云ふのである。こう云ふ種類の絵は普通馬鹿にされてわたもの である。何も個性々ヶの近代の事であるから、そう云ふ平凡な絵が下積にされ て、価値が認められなかつたのも無理はない。只好事家の趣味性に満足を与へ たぶけで、今でも多くの画家はそう云ふものを軽䁾してるる。併しそれ等のも のは今後見直されて、その価値が素直に認められる時が来ると思へる。

Yanagi explique ensuite que contrairement aux œuvres d'artistes célèbres, trop marquées par un style particulier et d'un prix souvent inaccessible, ces peintures discrètes sont en harmonie avec le mobilier et viennent enrichir le quotidien. Il $\mathrm{y}$ découvre une beauté particulière, qui vient d'abord de leur anonymat, alors que dans le monde artistique cette «absence de signature»(mumei 無銘) conduit généralement à porter un regard condescendant sur l'œuvre.

41 Enfin, Yanagi définit brièvement les principales caractéristiques des peintures populaires. Ce sont la modicité de leur prix, leur multiplicité, leur banalité, leur rapidité d'exécution, leur nature utilitaire, leur absence de prétention artistique ou encore le fait qu'elles étaient achetées par le peuple. Or, au regard des critères de l'histoire de l'art, de telles caractéristiques rendent ces peintures sans intérêt. Mais Yanagi parie sur un renversement de ces critères de jugement et pense qu'à l'avenir de nouveaux « critères du Beau » conduiront à leur reconnaissance.

En 1934, Yanagi consacra un autre texte, beaucoup plus long, à la question des doro-e, sous le titre plus général d'«Essai sur la peinture» (Kaiga-ron) ${ }^{45}$. Le préambule est particulièrement éclairant sur les motivations profondes de cette réflexion, à savoir promouvoir un art pictural qui dépasse la création individuelle :

D'aucuns penseront qu'il ne convient pas, dans une revue consacrée aux arts manuels, de débattre de théorie picturale, mais je considère pour ma part qu'il faut désormais au contraire traiter de la peinture du point de vue de ces derniers. Aujourd'hui, cela revient peut-être encore à prêcher dans le désert, mais je pense que notre époque se prépare désormais à accepter ce discours. Mon raisonnement n'a rien que de très banal, mais comme il me semble que personne n'a jusqu'à présent abordé cette question de manière claire et précise du point de vue du Beau, je souhaite poser avec netteté et concision les données du problème, pour expliquer l'esthétique que nous entendons forger à l'avenir. 
Je traiterai, à travers l'exemple des doro-e, de la nature et de la beauté de la peinture artisanale née du pinceau des gens de métier, en incitant à repenser la conception classique de la peinture individualiste et en expliquant la nécessité de promouvoir une beauté picturale en accord avec la vie quotidienne. À l'avenir, la peinture passera de l'art pur à l'art appliqué et sera appréciée non plus pour sa valeur artistique, mais pour sa dimension artisanale.

工藝の雑誌で絵画論を説くのは似合はぬと思はれるかも知れぬが、今後絵画は 寧ろ工藝の立場から論じらるべきだと云ふのが私の宿論である。まだ今の所で は野に叫ぶ者の声に過ぎかかも知れぬが、時代はもうそれを受け容机る準備を 始め出した様にも思ふ。論旨は寧ろ平凡なのであるが、美の方面からまだ 明確に此事を語つた人が無いと思ふので、将来建てらるべき美学の為に簡明に 記しておきたい。

泥絵を例として、画工の筆に成る工藝的な絵画の性質とその美を論じ、從来 の個人的絵画観の反省を求めて、生活と交わる絵画美の必要を説く。将来の絵 画の方向は純正より応用へと転じ、絵画が美術的なるが故にではなく工藝的な るが故に評価されるであろう。

43 Yanagi oppose ici la peinture au sens moderne, comme création individuelle (kojin-teki kaiga), et l'art des doro-e, qui se caractérise par sa dimension artisanale, au sens où il est le fruit non pas d'artistes de renom, mais de «peintres-artisans » (gakō), de gens de métier restés anonymes. Cette dernière notion de "peinture artisanale " (kōgei-teki kaiga) deviendra pour Yanagi un véritable mot-clé et il en traitera à nouveau dans un long article de $1937^{46}$.

À travers cette opposition apparaît la question de la hiérarchie des arts élaborée au début de Meiji de manière institutionnelle, suite notamment à la confrontation du Japon avec les catégories artistiques occidentales lors de sa participation aux expositions universelles. La naissance des catégories de bijutsu ("beaux-arts») et de kōgei («arts industriels» ou "arts manuels») - néologismes forgés dans les années 1870 - et l'émergence de la figure de l'artiste peintre comme créateur individuel ont conduit à négliger les formes picturales de l'époque prémoderne qui n'entraient pas dans le cadre de la définition occidentale de l'art, mais qui relevaient plutôt de l'imagerie populaire. Yanagi prône donc ici un retour à une conception ancienne des arts au Japon où, dans sa vision idéalisée, cette scission entre peinture et art manuel n'existait pas, ou du moins était moins fortement marquée. Il avait d'ailleurs débattu à plusieurs reprises au début des années 1930 de cette question des conséquences - en terme social et esthétique - de la formation à l'époque moderne de ces catégories artistiques cloisonnées et hiérarchisées ${ }^{47}$.

À cet égard, la transformation du nom de Nihon mingei bijutsukan (Musée des arts populaires du Japon) en celui de Nihon mingeikan (Maison des arts populaires du Japon) entre le projet de création de 1926 et son ouverture à Tōkyō en 1936 correspond à un choix délibéré d'abandonner ce terme bijutsukan, "musée des beaux-arts », trop connoté et mal adapté à la vision de Yanagi ${ }^{48}$.

Il est à noter par ailleurs que d'entrée de jeu Yanagi présente son essai non seulement comme une réévaluation d'un art pictural jusqu'alors ignoré, voire méprisé, mais qu'il lui assigne l'objectif de défendre une esthétique nouvelle, celle de l'art appliqué, de l'art lié à la vie quotidienne, vers lequel il veut entraîner les créateurs de son temps. En définitive, dans cet essai, les doro-e ne sont qu'un prétexte, qu'un exemple sur lequel il s'appuie pour proposer une nouvelle relation à la peinture. Il invite d'ailleurs les lecteurs qui n'apprécieraient pas cet exemple, à le remplacer par la peinture sur laque chinoise de l'époque des Han ou par les livres enluminés du Moyen Âge occidental. 
Mais que sont exactement ces doro-e, littéralement les " peintures à la boue »? Il s'agit d'une forme de peinture bon marché, recourant à des pigments minéraux dilués à l'eau, à la manière de la gouache dont elle présente la même texture opaque. Elles ne peuvent cependant se résumer à cette définition strictement technique qui repose sur leurs matériaux. Ce terme, qui commença, semble-t-il à n'être utilisé qu'au cours des années $1910^{49}$, désigne plutôt un genre, assez mal délimité, dont la caractéristique principale est le style naïf et le type de sujet. Ces peintures s'inscrivent dans le prolongement des vues d'optiques paysagères (appelées megane-e) produites au Japon dès le milieu du XVIII siècle, sous l'influence des gravures du même genre importées par les Hollandais, et on les a d'ailleurs parfois confondues avec celles-ci, car elles intègrent de la même manière des éléments plastiques de la peinture occidentale, comme l'effet de perspective centrale. Cependant, les doro-e sont plus tardives que ces dernières, car, précise Yanagi, elles furent réalisées en majorité à la fin de l'époque d'Edo, c'est-à-dire dans les années $1850-1860^{50}$. Elles étaient destinées à être vendues comme souvenirs aux voyageurs, de même que les Ōtsu-e. Leurs sujets représentent principalement des sites célèbres de la ville d'Edo et notamment les résidences seigneuriales et le château du shōgun.

\section{La pente Kinokuni et la résidence du fief de Kii à Edo}

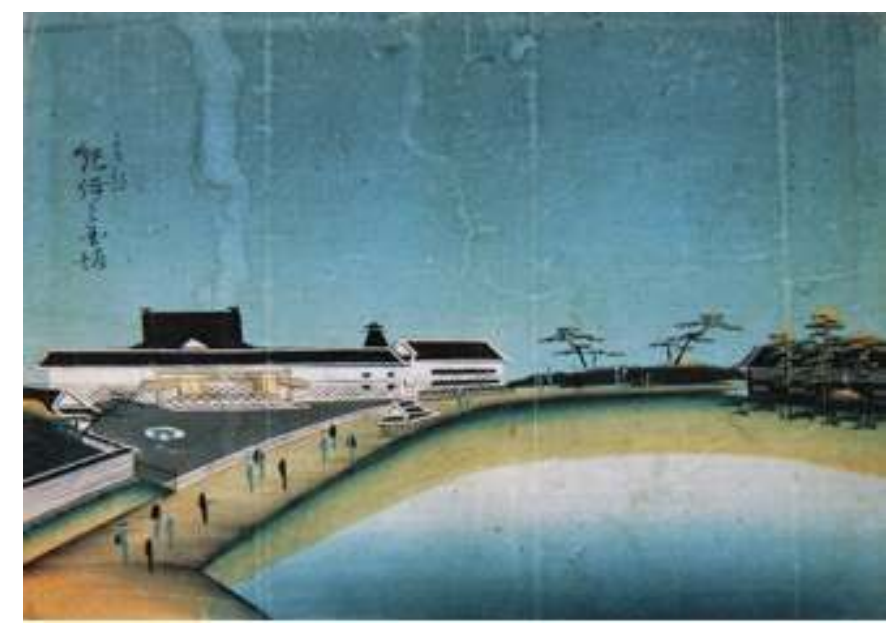

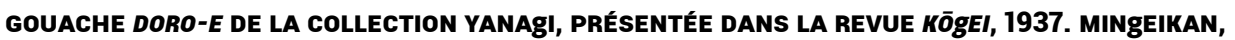
то̄кȲ̄.

Il existe néanmoins aussi des représentations de la route du Tōkaidō, de Kyōto et d'ōsaka, car cette production se développa également dans la région du Kamigata, et même, dans une moindre mesure, à Nagasaki ${ }^{11}$. 


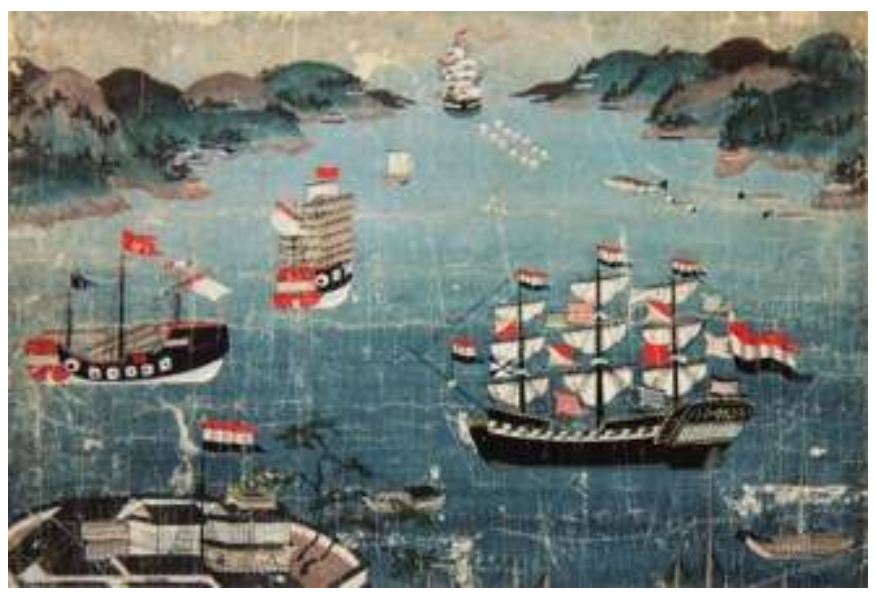

GOUACHE DORO-E DE LA COLLECTION YANAgI PRÉSENTÉE DANS LA REVUE KōgeI, 1937. MiNgEIKAN, то̄кYō.

Tout comme les peintures d'ōtsu, elles sont anonymes et ne cherchent pas à privilégier l'expression individuelle. Elles furent avant tout réalisées par des artisans pour subvenir à leurs besoins et non pour défendre une esthétique. Ces raisons expliquent selon Yanagi le désintérêt dont elles ont été victimes de la part des historiens d'art.

Or, face à ce type de peinture, Yanagi dit faire une expérience singulière. Il ne peut s'empêcher de voir dans ces œuvres dont le nom du créateur reste inconnu et la nature primitive, une forme de beauté qui le transporte dans un univers étrange où lui-même devient un «créateur ». Car ces peintures dont la contemplation jamais ne le lasse, possèdent la capacité de faire voyager son imaginaire et de le plonger dans un univers presque onirique. Cette expérience est d'autant plus étrange que ces peintures ne possèdent aucune des qualités que l'on attribue généralement à l'art pictural. Et pourtant elles exercent sur lui une fascination, un attrait irrésistible que ressentent même ceux qui, ne leur accordant pas de valeur, seraient prêts à s'en débarrasser.

51 Yanagi déduit de cette expérience qu'il existe, pour produire une peinture de qualité, une autre voie possible que celle tracée par les créateurs de renom. Il va même plus loin, affirmant que ces œuvres populaires possèdent une beauté singulière que seule peut produire ce type de peinture élémentaire réalisée par des artisans anonymes. L'absence de raffinement technique et la banalité apparente de ces peintures ne les empêchent en rien de susciter un choc esthétique, bien au contraire. Pour Yanagi, la peinture ne doit donc plus être le privilège des génies et des créateurs célèbres. Il faut célébrer également les œuvres produites par les gens ordinaires. La beauté peut aller de pair avec une forme de banalité. La peinture n'est pas contradictoire avec le travail artisanal.

La première caractéristique des doro-e est d'être des productions " non individuelles » en ce sens qu'elles présentent des conventions plastiques communes, quel que soit le sujet, et qu'elles furent exécutées selon le principe de la division du travail et non par un seul artiste. C'est aussi l'une des principales causes du mépris dont elles ont été les victimes. Pour Yanagi, il faut donc se débarrasser des préjugés selon lesquels une œuvre qui ne possède pas de caractéristique individuelle, qui n'est pas marquée par l'empreinte d'un auteur clairement identifiable, ne peut recéler une forme de beauté. 

pourquoi ils ne vénèrent que les œuvres individuelles. N'y aurait-il pas, pour la peinture, un autre territoire, libéré de l'emprise individuelle? Car si la beauté ne saurait nier totalement l'individu, elle ne saurait non plus se limiter à ce dernier. Sur ce point Yanagi affine sa pensée et précise que l'art qu'il appelle de ses vœux doit être une peinture «non individualiste» (hi-kojin 非個人), mais pas pour autant «dénuée d'individualité » (mu-kojin 無個人). Il évoque la possibilité d'une production picturale collective, fruit d'une organisation dans laquelle les tâches seraient partagées, et il fait l'éloge de la « collaboration » (kyōryoku 協力) dans l'acte créatif.

Pour Yanagi, la responsabilité des historiens est grande dans la conception étroite de la peinture qui a cours. L'histoire de la peinture, fruit d'une époque moderne fondée sur le culte de l'individu, consiste souvent en un commentaire d'œuvres en fonction du nom des artistes. Elle se résume à une suite de biographies de génies célèbres. Le travail des historiens d'art vise principalement à « attribuer » les œuvres à tel ou tel artiste. Il en va de même pour l'histoire de l'ukiyo-e, alors qu'on ne peut, selon Yanagi, résumer cet art au problème de l'auteur. Car dans la plupart des cas, l'œuvre finale, à savoir la gravure, dépasse la beauté du dessin original signé. C'est donc le travail des artisans anonymes, graveurs, estampeurs (voire fabricants de papiers et de couleurs), qu'il faut prendre en considération. L'ukiyo-e est l'exemple même d'un art collectif, issu de la collaboration de différents corps de métier. Néanmoins, les historiens ne retiennent que les noms des « artistes » qui ont produit les dessins à partir desquels sont réalisées les estampes. Yanagi rejoint ici le point de vue de Nagai Kafū, qui soutenait lui aussi que dans le domaine de l'ukiyo-e la gravure l'emporte par ses qualités propres sur la peinture originale ${ }^{52}$.

55 En revanche, la beauté des peintures ukiyo-e de la période primitive - qui, à la même époque, avaient émerveillé un artiste comme Kishida Ryūsei (1891-1929) par exemple ${ }^{53}$ - s'explique par le fait qu'il s'agit non pas d'un art marqué par l'empreinte individuelle, mais qui s'inscrit dans une tradition, dans un courant. De ce point de vue, ces œuvres, de même que les estampes primitives de l'école Torii au début du XvIII ${ }^{\mathrm{e}}$ siècle par exemple, sont peu influencées par le génie individuel. Il s'agit d'une «beauté formelle » (yōshiki no bi 様式の美), fondée sur la reproduction de compositions et de traits hérités d'une tradition.

Ce type de peinture permet la multiplicité et, partant, de lier beauté et quantité, alors que la singularité est généralement considérée comme la valeur absolue dans la peinture individuelle. Aux yeux de Yanagi, cette possibilité de la multiplicité présente un intérêt du point de vue social, car elle permet à ces œuvres d'être peu chères. Yanagi évoque dans cette optique des débouchés dans la publicité ou dans l'illustration, domaines perçus comme secondaires du point de vue d'un art strictement individuel.

De ce point de vue, le Moyen Âge européen est donc présenté comme une période idéale où la peinture - qu'il s'agisse des fresques murales ou des illustrations livresques - était issue de la collaboration des artisans, la Renaissance ayant introduit la peinture individuelle. Yanagi entend revenir à cet état où la peinture possédait un caractère "public» et "multiple». Dans cette perspective, les arts fondés sur la 《reproduction» (tensha 転写) offrent une nouvelle approche prometteuse. La gravure notamment (xylogravure, eau-forte, lithographie) présente cette dimension non individuelle, sociale et économique. La reproduction en fac-similé - qui loin de déprécier l'œuvre d'art est "capable de créer une beauté supérieure à celle de 
l'original»-, de même que la peinture murale, permettra d'élever la conscience artistique dans la société. Yanagi fait donc un constat inverse de celui de Walter Benjamin qui, à la même époque, dans L'Euvre d'art à l'époque de sa reproductibilité technique, s'élevait contre la perte de l'unicité, de l'aura et de la fonction rituelle de l'œuvre d'art, engendrée par sa diffusion par la reproduction mécanique de masse ${ }^{54}$.

Yanagi entend surtout réhabiliter le lien entre le Beau et l'utile, notions considérées comme incompatibles, voire antinomiques depuis qu'à l'époque moderne s'est brisée la relation entre la peinture et la société. Dans son projet - contrairement à la conception dix-neuviémiste de l'art pour l'art où Benjamin voyait une "théologie négative » qui refuse toute fonction sociale -, la peinture devra être "fonctionnelle ", dans le sens où elle sera en lien avec la vie quotidienne. Cependant, cette fonctionnalité, dans la société moderne, a souvent conduit à la laideur, alors que tel ne fut pas le cas, aux yeux de Yanagi, aux époques antérieures.

Yanagi oppose la «beauté sublime» (sūkō-bi 崇高の美) - héritage d’une époque marquée par le culte des héros - et la «beauté simple» (heii-sa no bi 平易さの美) et " ordinaire ", qui fait défaut à la peinture moderne. La difficulté étant que l'homme moderne, qui n'apprécie que ce qui sort du commun, parvient difficilement à découvrir la beauté des choses ordinaires. Or, les doro-e, avec leur beauté ordinaire et banale, apportent une solution, montrent une voie possible.

Enfin, Yanagi entend réhabiliter la dimension décorative de la peinture en renouant avec le «motif décoratif » (moyō 模様) et la stylisation, qui sont caractéristiques des doro-e, ces peintures qui « dépassent la description ». L'intérêt étant que le motif est multiple et reproductible, alors que la peinture est unique.

61 En conclusion, dans cet "Essai sur la peinture » de 1934, Yanagi va bien au-delà de son étude sur les Ōtsu-e, qui était avant tout historique, pour, à travers l'exemple des doro-e, proposer un modèle pour la création contemporaine. Il s'élève contre l'art « individuel » qu'il avait tant défendu dans sa jeunesse et propose un art "collectif », à dimension «sociale» et "reproductible». Force est cependant de reconnaître que contrairement à d'autres domaines, comme la céramique, où cette esthétique du mingei a trouvé un large écho, les idées de Yanagi sur la peinture n'ont pas conduit à cette " révolution du concept de peinture ", à ce renversement des valeurs qu'il avait formé de ses vœux.

\section{En guise de conclusion}

Dans le domaine de la peinture, Yanagi s'est intéressé exclusivement à des genres spécifiques de l'époque d'Edo. Cette période représentait en effet pour lui un moment unique dans l'histoire du Japon où «la culture fut la propriété du peuple $»^{55}$. Il a cherché à poser un autre regard sur l'art pictural de cette période, qui était généralement abordé par les historiens du point de vue de la biographie des artistes et de la création individuelle, à l'exemple de l'ouvrage de Fujioka Sakutarō 藤岡作太郎, Kinsei kaiga-shi 近世絵画史 (Histoire de la peinture des Temps modernes), le premier publié au Japon sur le sujet, en 1903. Pour Yanagi, de même que l'histoire ne saurait être une suite de biographies de héros aux dépens de l'analyse de la vie du peuple, l'histoire de l'art ne peut se réduire à l'enchaînement des génies. De ce point de vue, son approche a permis de sortir d'une méthodologie inspirée de l'historiographie occidentale, fondée traditionnellement sur les créateurs eux-mêmes et reposant sur 
une vision évolutionniste des styles. Elle annonce les travaux récents sur l'art d'Edo qui prennent en considération les modes de "production » et la "destination » de la peinture et de l'image imprimée ${ }^{56}$.

Il n'en reste pas moins que la définition restrictive que Yanagi a donné de la " peinture populaire ", en excluant par exemple l'ukiyo-e, n'est pas sans poser un certain nombre de problèmes, qui expliquent d'ailleurs en partie l'échec relatif de son projet. Cho Chayong a soulevé la question à propos de la peinture coréenne en particulier, en faisant remarquer qu'il semblait difficile d'opérer un tel changement de perspective en considérant comme "peinture populaire" uniquement les productions naïves d'artisans ne possédant pas de bases artistiques ${ }^{57}$.

Malgré les efforts répétés de Yanagi pour promouvoir une nouvelle forme de peinture " collective ", inspirée de l'esprit artisanal des peintures rustiques de l'époque d'Edo, ce domaine est certainement celui dans lequel les idées du mouvement Mingei se sont le moins imposées, si l'on met à part quelques expériences remarquables, comme les gravures de Munakata Shikō 棟方志功dans l'esprit de l'estampe bouddhique, ou les créations textiles de Serizawa Keisuke, influencées par les peintures coréennes composées d'idéogrammes stylisés et par les tissus traditionnels d'Okinawa teints au pochoir (bingata 紅型).

Si le projet d'une nouvelle peinture a été peu suivi, le travail historique mené par Yanagi n'en reste pas moins une contribution essentielle pour notre compréhension de l'art et de la culture de l'époque d'Edo. On peut s'interroger dans cette perspective sur la parenté du regard de Yanagi avec celui de certains folkloristes qui furent ses contemporains, à commencer par Yanagita Kunio 柳田國男 (1875-1962), le père des études sur le folklore japonais. Yanagi a fait lui-même une mise au point sur cette question, à l'occasion d'un entretien avec le célèbre ethnofolkloriste en $1940^{58}$, puis lors d'une conférence au département d'anthropologie de l'Université impériale de Tōkyō l'année suivante ${ }^{59}$. Il en ressort que si ces deux disciplines ont des points communs, notamment par l'intérêt qu'elles portent à la «vie quotidienne du peuple» et aux «cultures régionales», elles présentent une "différence de positionnement" essentielle. Les études folkloriques (minzokugaku), qui ont pour objet, selon Yanagita, la connaissance précise de l'histoire ancienne à travers l'étude objective des coutumes, des objets quotidiens ou des traditions populaires, relèvent d'une science " empirique " (keikengaku) ou "descriptive» (kijutsugaku). Inversement, l'étude de l'artisanat populaire (mingeigaku), qui se projette dans le futur, s'apparente à une science "normative " (kihangaku), car elle a pour ambition de définir une esthétique d'après des jugements de valeur. Ainsi, par exemple, lorsque ces deux disciplines s'intéressent aux plaquettes votives figuratives (ema), explique Yanagi, leurs méthodes et leurs objectifs diffèrent fondamentalement, car la première cherche à rassembler un échantillon représentatif en vue d'une étude des croyances populaires, des coutumes régionales ou des légendes, tandis que la seconde opère des choix esthétiques et une hiérarchisation selon le critère du Beau. L'une s'intéresse au contenu et à ce que l'objet révèle d'une pratique - et finalement de l'identité culturelle -, l'autre s'intéresse à l'objet pour sa valeur avant tout esthétique ${ }^{60}$.

66 Une autre comparaison éclairante sur cette différence d'approche, en ce qui concerne la question de la peinture populaire, nous est fournie par l'enquête ethnographique qu'André Leroi-Gourhan mena au Japon à la fin des années 1930 et qui le conduisit à s'intéresser lui aussi aux «productions minimes » de l'art populaire, en particulier aux 
plaquettes votives et aux peintures d'ōtsu. Leroi-Gourhan en réunit une petite collection $^{61}$ - destinée au Musée d'ethnographie du Trocadéro - qui lui servit de matériau pour entreprendre la rédaction d'un ouvrage sur les Formes populaires de l'art religieux au Japon ${ }^{62}$, à une époque où il cherchait à « évaluer l'aide que l'art populaire actuel ou récent peut apporter à l'histoire de l'art des grands peuples " ${ }^{63}$. Au premier abord, l'angle d'attaque de Leroi-Gourhan est semblable à celui de Yanagi - dont il découvrit au Japon le musée et l'ouvrage sur les peintures d'ōtsu ${ }^{64}-$, lorsqu'il écrit en préambule de son livre: «L'histoire de la peinture est faite de grands noms d'hommes. Pour échapper, il faut partir d'un art qui ne porte pas de noms d'hommes, quitter provisoirement les œuvres maîtresses qui sont des tours de force techniques, des défis au papier et au pinceau; prendre des œuvres anonymes, interchangeables, des choses qui sont à l'étage de milliers d'artistes modestes. $\nu^{65}$ Le travail de Yanagi semble également proche de celui de l'ethnologue, lorsqu'il effectue des classements typologiques reposant avant tout sur les thèmes et le sens des peintures. Leurs motivations furent néanmoins très différentes, car Yanagi ne chercha pas à étudier ce que Leroi-Gourhan appelle la "valeur ethnique » de ces images, ni à comprendre l'évolution historique des thèmes de la peinture populaire pour forger une théorie générale de la figuration. Conformément à son projet muséal défini dès 1926 d'« inscrire dans l'histoire la beauté » de l'art populaire en sélectionnant les œuvres les plus remarquables selon des critères esthétiques ${ }^{66}$, il eut pour ambition d'élever ces peintures au rang de l'art, dans une nouvelle définition élargie. Il fut avant tout un militant de la cause de l'art populaire, cherchant à promouvoir une autre forme de beauté et à proposer des modèles pour renouveler la création contemporaine. LeroiGourhan, pour sa part, tout en admirant le travail de certains artistes du Mingei, comme le potier Kawai Kanjirō 河井寛次郎 qui lui servit de guide dans ce domaine ${ }^{67}$, ne partagea pas semble-t-il cet enthousiasme pour un art néopopulaire, écrivant depuis Kyōto en 1938 : « Les choses en sont à ce point que les artistes créent en ce moment un courant de snobisme d'art paysan. Ce qui veut bien dire que l'art paysan est mort. $~^{68}$

Le rapport de Yanagi à l'objet resta une relation avant tout sensible et intuitive, celle d'un esthète, d'un amateur épris du goût de la collection. C'est justement ce regard qui a permis de faire sortir ces peintures de leur statut de simple document ethnographique ou ethnoreligieux en révélant leurs qualités esthétiques.

\section{NOTES}

1. Sur les cent vingt-neuf numéros de cette exposition, les deux seules œuvres graphiques étaient des créations modernes : une estampe sur bois de Munakata Shikō de la série du Sūtra de Kannon (1938) et une teinture au pochoir sur tissu de Serizawa Keisuke représentant des Scènes de vie aux Ryūkyū (1939).

2. Yanagi rédige au début des années 1910 - alors qu'il n'a qu'une vingtaine d'années - une série de textes consacrés à des artistes comme Beardsley (1910), Rodin (1910 et 1912), Renoir (1911), Van Gogh (1912) ou Matisse (1913), qui seront publiés dans les premiers numéros de la revue Shirakaba. Il envisage les caractéristiques communes des artistes postimpressionnistes dans un 
essai célèbre intitulé « Kakumei no gaka » 革命の畫家 (Les peintres de la révolution), Shirakaba, janvier 1912, repris dans Yanagi Sōetsu zenshū 柳宗悦全集 (par la suite YSZ), t. 1, Tōkyō, Chikuma shobō, 1981, p. 543-567. Voir sur ce point l'article de Michael Lucken dans ce numéro.

3. Cf. Yanagi Sōetsu, «Chōsen minzoku bijutsu tenrankai ni tsuite » 朝鮮民族美術展覧會に就て (À propos de l'Exposition des arts populaires coréens), Shirakaba, $\mathrm{n}^{\circ} 21$, mai 1921 et Yomiuri shinbun, 9-10 mai 1921, repris dans YSZ, t. 6, 1981, p. 84-88. L'exposition, qui comportait un peu moins de deux cents œuvres, se tint à la galerie Ruissō 流冕荘 (Ruisseau) dans le quartier d'Ogawa-chō à Kanda, l'un des premiers lieux de ce genre au Japon : ouverte en 1914, elle abrita certaines des manifestations des artistes du groupe Shirakaba.

4.「西洋の藝術に親んだ吾々は、いつか自らの故郷である東洋の藝術を省みる時が来るで あらう」, ibid., p. 85.

5. Cf. Yanagi Sōetsu, “"Chōsen minzoku bijutsukan" no setsuritsu ni tsuite "「朝鮮民族美術 館」の設立に就て (À propos de la création d'un Musée des arts populaires coréens), Shirakaba, janvier 1921 (puis publié en anglais dans The Japan Advertiser le 23 janvier), repris dans YSZ, t. 6, 1981, p. 79-83.

6. Cf. Yanagi Sōetsu, «Ushinawaren to suru ichi Chōsen kenchiku no tame ni »失なわれんとす る一朝鮮建築のために (Pour la défense d'une œuvre architecturale coréenne en péril), Kaizō, septembre 1922, repris dans YSZ, t. 6, 1981, p. 145-154. Dans son étude sur Yanagi, Élisabeth Frolet, citant les travaux de Takasaki Sōji 高崎宗司 (Chōsen no tsuchi to natta nihonjin. Asakawa Takumi no shōgai 朝鮮の土となった日本人一浅川巧の生涯, 1982), relativise l'action de Yanagi en précisant que l'ouverture du musée sera acquise "grâce à la décision du gouverneur général [de la Corée] de masquer son oppression sur le pays par une "politique culturelle (bunka seiji)" ». Cf. Yanagi Sōetsu ou les éléments d'une renaissance artistique au Japon, Paris, Publications de la Sorbonne, 1986, p. 66.

7. Yanagi Sōetsu, «Chōsen-ga o nagamete» 朝鮮畫を眺めて (En contemplant une peinture coréenne), Mingei, n 59, novembre 1957 ; «Fushigi-na chōsen minga » 不思議な朝鮮民畫 (Les merveilleuses peintures populaires coréennes) ; «Chōsen no minga » 朝鮮の民畫 (La peinture populaire coréenne), Mingei, $\mathrm{n}^{\circ}$ 80, août 1959, repris dans YSZ, t. 6, 1981, p. 496-499, p. 500-512, p. 513-518. Sur Yanagi et la peinture coréenne, voir Ogyū Shinzō 尾久彰三, «Yanagi Muneyoshi ga hakken shita minshū-teki kaiga no“!”»柳宗悦が発見した民衆的絵画の「!」，Bessatsu Taiyō: Kankoku, Chōsen no kaiga 別冊太陽 — 韓国・朝鮮の絵画, Tōkyō, Heibonsha, novembre 2008, p. 112-113.

8. Sur ce genre, voir Yeolsu Yoon, Folk Painting. Handbook of Korean Art vol. 4, Londres, Laurence King Publishing, 2003, p. 194-211; catalogue de l'exposition Nostalgies coréennes. Collection Lee Ufan. Peintures et paravents $d u X_{X V I}^{e}$ au XIX siècle, Paris, Musée national des arts asiatiques - Guimet, Réunion des musées nationaux, 2001, p. 146-162.

9. Yanagi Sōetsu, « Fushigi-na chōsen minga », op. cit., YSZ, t. 6, 1981, p. 510.

10. Yanagi Sōetsu, « Chōsen no minga », op. cit., YSZ, t. 6, 1981, p. 515.

11. Cho Cha-yong (transcrit parfois Zo Zayong), architecte coréen formé à Harvard, fut l'un des premiers à constituer à partir des années 1960 une collection de minhwa (conservée au Musée Emille qu'il fonda à Séoul en 1967), à organiser des expositions et à publier sur le sujet. Voir notamment Zozayong, Guardians of Happiness. Shamanistic Tradition in Korean Folk Painting, Séoul, Emileh Museum, 1982 ; Cho Cha-yong 趙子庸, Kim Ch’ŏl-sun 金哲淳, Chosŏn sidae minhwa 朝鮮時 代民畫, Séoul, Yegyŏng Sanŏpsa, 1989 ; Cho Cha-yong, Lee U-fan, Traditional Korean Painting. A Lost Art Rediscovered, Tōkyō, Kodansha International, 1990.

12. Cf. Hong Sŏn-pyo 洪善杓, «Chōsen minga no atarashii rikai » 朝鮮民画の新しい理解, Bessatsu Taiyō. Kankoku, Chōsen no kaiga, Tōkyō, Heibonsha, novembre 2008, p. 108-110.

13. Catalogue de l'exposition Pan'gapta! uri minhwa / Ureshii! Chōsen minga / Happy! Joseon Folk Painting, Séoul, Sŏul yŏksa pangmulgwan, 2005. À propos de la contribution de Yanagi, voir Ogyū 
Shinzō 尾久彰三, ““Ureshii ! Chōsen minga” ten ni yosete»「うれしい! 朝鮮民画」展に寄 せて, p. 246-251.

14. À propos de l'évolution des recherches sur la peinture populaire coréenne depuis Yanagi, voir Chŏng Pyŏng-mo 鄭炳模, “Chōsen minga-ron» 朝鮮民画論 (Les discours sur la peinture populaire coréenne), ibid., p. 262-271.

15. D'après l'introduction de son livre Shoki Ōtsu-e 初期大津繪 (Les débuts de la peinture d'Ōtsu, 1929), repris dans YSZ, t. 13, 1982, p. 28.

16. Voir notamment une série de textes de Yanagi sur le Tsukishima monogatari emaki 築嶋物語絵 巻 (Le rouleau du conte de l'île artificielle), une peinture narrative sur rouleau datée du XVI siècle, inspirée d'un conte édifiant de l'époque Muromachi, parus dans un numéro spécial de la revue Kōgei (Artisanat) en juin 1936, repris dans YSZ, t. 13, 1982, p. 400-422.

17. Yanagi évoque sa conception extensive de la peinture populaire dans « Minga ni tsuite » 民畫 について (À propos de la peinture populaire), Mingei zukan 民藝圖鑑, t. 1, Tōkyō, Hōbunkan, 1960, repris dans YSZ, t. 13, 1982, p. 502-516.

18. Yanagi Sōetsu, Zakki no bi 杂隹器の美 (La beauté des objets usuels), 1927. D’après Mizuo Hiroshi 水尾比吕志, 《Kosei-bi o koeru mono » 個性美を超えるもの, YSZ, t. 13, 1982, p. 743.

19. On rappellera que les premiers travaux historiques et anthropologiques sur les plaquettes votives ne remontent qu'aux années 1920-1930. Citons l'étude de Frederick Starr, «Ema» (Transactions of The Asiatic Society of Japan, vol. 48, 1920, traduction japonaise publiée par le musée Tōyō minzoku hakubutsukan de Nara, en 1930) et celles des folkloristes Yanagita Kunio («Ema to uma » 繪馬と馬 / 《Les plaquettes votives et les chevaux») et Nakayama Tarō 中山太郎 («Ema genryū-kō » 繪馬源流考 / 《Réflexions sur l'origine des plaquettes votives ») publiées dans un numéro spécial de la revue Tabi to densetsu en 1930. La revue Kōgei fondée par Yanagi consacra un numéro spécial à ce sujet en 1937, avec notamment une contribution du peintre Serizawa (« Ema ni tsuite» 繪馬について / «À propos des plaquettes votives») et une étude par l'historien Nakamura Naokatsu 中村直勝: «Ema shōshi» 繪馬小史 («Petite histoire des plaquettes votives »).

20. Cf. Yanagi Sōetsu, 《Nihon mingei-hin tenrankai mokuroku» 日本民藝品展覧會目録 (Catalogue de l'exposition d'œuvres d'art populaire japonais), 15-17 mars 1929, repris dans YSZ, t. 8, 1980, p. 357-359. Cette exposition, qui fut organisée dans les bureaux de Kyōto du journal Mainichi, comportait 55 peintures, dont 21 Ōtsu-e (propriété de Yanagi), 11 gouaches doro-e et 19 plaquettes votives en possession de Serizawa Keisuke.

21. Voir les huit critères retenus par Yanagi pour les œuvres conservées au Mingeikan, dans Élisabeth Frolet, op. cit., p. 108.

22. Le livre fut publié dans une collection d'ouvrages consacrés aux arts populaires («Mingei sōsho ») dont il constitua le second volume. Le premier volume, également de Yanagi, portait sur La beauté des objets usuels (Zakki no bi), 1927.

23. Le premier historien d'art à se pencher sérieusement sur le sujet sera Taki Seiichi 瀧精一 (1873-1945), titulaire de la chaire d'histoire de l'art japonais à l'Université impériale de Tōkyō de 1914 à 1943. Dans un essai publié dans la prestigieuse revue Kokka 國華 en janvier 1940 ( Ōtsu-e setsu » 大津繪説 / «Thèses à propos des peintures d'ōtsu »), il avoue lui-même que : «L'ouvrage de Yanagi Sōetsu Les débuts de la peinture d'ōtsu est digne d'éloges. Cependant, les recherches sur la place historique des images d'ōtsu considérées du point de vue de la peinture ne semblent pas encore suffisantes.» Taki Setsuan bijutsu ronshū. Nihon-hen 瀧拙庵美術論集 一日本篇, Tōkyō, Zaūhō kankōkai, 1943, p. 383.

24. Morii Toshiki 森井利喜, Ōtsu-e senshū 大津繪選集, Ōtsu, Ōtsu-e kai, avril 1926. À propos de cette exposition, voir YSZ, t. 13, 1982, p. 147-148.

25. Katagiri Shūzō (dir.), Genshoku Ōtsu-e zufu 原色大津絵困譜, Ōtsu, Ōmi kyōgei bijutsukan, Daihonzan Enman-in monzeki, 1971; Katagiri Shūzō, Ōtsu-e kōwa 大津絵こう話, Hikone, Ōtsu-e bunka kyōkai, 1984. 
26. Dans Shoki Ōtsu-e Yanagi a établi une liste de 102 sujets, classés par grands genres : images bouddhiques, Sept dieux du Bonheur, démons, personnages historiques ou légendaires, personnages masculins, personnages féminins, animaux, oiseaux, plantes, architecture.

27. La collection de peintures d'Ōtsu du Musée des arts populaires de Tōkyō comporte 138 pièces, qui ont été publiées dans Ogyū Shinzō 尾久彰三 (dir.), Ōtsu-e. Nihon mingeikan shozō 大津絵一日 本民藝館所蔵, Tōkyō, Tōhō shuppan, 2005. Elles proviennent en grande partie du don posthume en 1985 d'un particulier, Komenami Shōichi 米浪庄式, qui avait réuni juste après la Seconde Guerre mondiale la plus importante collection d'ōtsu-e, avec plus d'une centaine de pièces.

28. Le Musée d'histoire de la ville d'Ōtsu possède également une soixantaine d'œuvres (présentées en partie dans deux expositions : Kaidō no minga. Ōtsu-e 街道の民画一大津絵, 1995, et Ōtsu-e no sekai 大津絵の世界, 2006) et le Musée municipal de Machida 46 pièces, qui ont été publiées récemment (Ōtsu-e. Machida shiritsu hakubutsukan zōhin zuroku 大津絵 一町田市立博物館 蔵品図録, 2006). La publication la plus ambitieuse consacrée aux peintures d'ōtsu en recense 230 (Kaidō ni umareta minga. Ōtsu-e 街道に生まれた民画一大津絵, Kyōto, Kōrinsha, 1987).

29. Mizuo Hiroshi, sur la base d'une estimation d'une cinquantaine d'images vendues chaque jour par les échoppes des peintres d'ōtsu et de ses environs, parvient à un chiffre de plus de trois millions et demi de peintures pour toute l'époque d'Edo. Cf. Kokka 國華, «Tokushū : Ōtsu-e » 特 集 —大津繪, n² 1267, mai 2001, p. 21.

30. Dans Ukiyo-e zakki 浮世繪襍記 (Notes sur l'ukiyo-e, 1943) Nakada Katsunosuke 仲田勝,之助 a avancé des arguments pour faire remonter l'apparition des Ōtsu-e à l'ère Kan.ei (1624-1644) et tenté de prouver que des peintures à caractère "satirique» (giga 戯画) auraient existé avant l'apparition des thèmes bouddhiques. Yanagi a réfuté ces arguments dans «Ōtsu-e gaisetsu » 大 津繪概説 (Exposé sommaire sur les peintures d'Ōtsu), Kōgei, $\mathrm{n}^{\circ}$ 120, janvier 1951, repris dans YSZ, t. 13, 1982, p. 203-205.

31. «Ōtsu-e no waka » 大津繪の和歌 (Les poèmes des peintures d'Ōtsu), Kōgei, nº 2, février 1931, repris dans YSZ, t. 13, 1982, p. 177-202.

32. «Ōtsu-e no hanashi» 大津繪の話 (Propos sur les peintures d'Ōtsu), conférence radiophonique diffusée à Kyōto le 18 janvier 1929, repris dans YSZ, t. 13, 1982, p. 22.

33. Voir sur ce point notre analyse de l'ouvrage de Kafū, Edo geijutsu-ron 江戸藝術論 (Essais sur les arts d'Edo, 1920), dans Christophe Marquet, «Le regard de Nagai Kafū : une relecture des arts d'Edo au début du Xx ${ }^{\mathrm{e}}$ siècle ", Cipango. Cahiers d'études japonaises, INALCO, nº 12, 2005, p. 308-329.

34. Voir Nathalie Heinich, Du peintre à l'artiste. Artisans et académiciens à l'âge classique, Paris, Les éditions de Minuit, 1993 et L'élite artiste. Excellence et singularité en régime démocratique, Paris, Gallimard, 2005.

35. Yanagi développera cette question dans « Kōgei to bijutsu 》工藝と美術 (Les arts industriels et les beaux-arts), Mingei, $\mathrm{n}^{\circ}$ 27, mars 1933, repris dans YSZ, t. 8, 1980, p. 554-570.

36. Yanagi déclarera ainsi dans une conférence donnée en 1936 au Club des Pairs à Tōkyō: "Ukiyo-ye is known the world over, partly because the artists are those of well-established reputation. It is a pity that little attention is paid to otsu-ye which is not inferior to the betterknown ukiyo-ye in beauty and grace. " Yanagi Sōetsu, traduit par Sakabe Shigeyoshi, Folk-Crafts in Japan, Tōkyō, Kokusai bunka shinkōkai, 1936, p. 36.

37. Sur les deux séjours de Yanagi aux États-Unis (1929-1930 et 1952-1953), voir Nicole Coolidge Rousmaniere, "Yanagi's America : Soetsu Yanagi's Two Extended Stays in the United States and Their Impact on America ", catalogue de l'exposition Mingei. Two Centuries of Japanese Folk Art (Peabody Essex Museum, Joslyn Art Museum, etc.), The Japan Folk Crafts Museum, 1995, p. 48-55. 38. D'après une lettre adressée à Bernard Leach le 15 septembre 1929, reprise dans YSZ, t. 21-1, 1989 , p. 374.

39. Ce travail auquel Yanagi apporta son aide, et qui constitua la première présentation circonstanciée de l'histoire de la céramique coréenne aux États-Unis, fut publié dans le vol. II 
d'Eastern Art en 1930 sous le titre "Kōrai Celadon in America". Yanagi publia dans le même numéro "A Note on the Pottery Kilns of the Kōrai Dynasty".

40. Langdon Warner, The Craft of the Japanese Sculptor, New York, MacFarlane, 1936, p. 53-54. Sur Mokujiki, voir l'article de François Macé dans ce numéro.

41. Langdon Warner, The Enduring Art of Japan, Cambridge, Harvard University Press, 1952, chapitre "Folk and Traditional Art", p. 76-84, dans lequel est longuement cité l'article de Yanagi sur les peintures d'ōtsu. Warner y reproduit une vingtaine d'exemples de peintures, de sculptures, de céramiques ou d'objets relevant de l'art populaire (fig. 62 à 78).

42. Eastern Art, College Art Association, Philadelphia, vol. II, 1930, p. 5-36.

43. Cf. "Japanese Peasant Painting", Fogg Art Museum. Harvard University. Notes, vol. II, $\mathrm{n}^{\circ}$ 5, juin 1930, p. 228. Notons qu'une autre exposition de peintures d'ōtsu, comportant 44 pièces, avait été organisée deux ans plus tôt à Londres par le marchand d'art Yamanaka, accompagnée d'un modeste catalogue : Otsuye: Old Japanese Caricatures, London, Yamanaka \& Compagny, 1928, 18 p.

44. Yanagi Sōetsu, «Sashi-e kaisetsu. Minga ni tsuite» 挿繪解説一民畫に就て (Commentaire des illustrations. À propos de la peinture populaire), Kōgei, nº 2, 1931, repris dans YSZ, t. 13, 1982, p. 369-375.

45. Yanagi Sōetsu, «Kaiga-ron » 繪畫論 (Essai sur la peinture), Kōgei, nº 37, janvier 1934, repris dans YSZ, t. 13, 1982, p. 382-399, avant-propos p. 769.

46. Yanagi Sōetsu, «Kōgei-teki kaiga »工藝的繪畫 (La peinture artisanale), Kōgei, n 73, février 1937, repris dans YSZ, t. 13, 1982, p. 423-436. Cet article fut publié dans un numéro spécial de la revue Kōgei consacré aux doro-e.

47. Yanagi Sōetsu, «Bijutsu to kōgei » 美術と工藝 (Les beaux-arts et les arts industriels), Ōsaka Mainichi shinbun, 10-12 février 1931, repris dans YSZ, t. 8, 1980, p. 432-436 ; Yanagi Sōetsu, « Kōgei to bijutsu »工藝と美術 (Les arts industriels et les beaux-arts), Mingei, $\mathrm{n}^{\circ}$ 27, mars 1933, repris dans YSZ, t. 8, 1980, p. 554-570.

48. Yanagi s'en explique dans «Nihon mingeikan annai »日本民藝館案内 (Présentation de la Maison des arts populaires), Gekkan Mingei, septembre 1939, repris dans YSZ, t. 16, 1981, p. 93.

49. Voir sur ce point Yoshida Shōgorō 吉田小五郎, «Doro-e no hanashi » 泥繪の話 (Propos sur les peintures à la gouache), Kōgei, $\mathrm{n}^{\circ} 73$, mars 1937.

50. La question de la datation des doro-e reste un objet de débat, mais leur production ne remonte sans doute pas au-delà du début $d u x x^{e}$ siècle. Elles ne sont probablement pas en effet antérieures à l'apparition des thèmes paysagers dans l'ukiyo-e, qui débute dans les années 1830 avec des artistes comme Hiroshige et Hokusai. L'usage généralisé du bleu de Prusse dans ces peintures confirme que leur production commença au plus tôt dans les années 1820. Voir Satō Morihiro, Edo doro-e: Gaze on Urban Space in Early Modern Japan, Master's Essay, Columbia University, Master of Arts in Liberal Studies, East Asian Studies, 1996. Résumé en japonais sur le site http://web.kyoto-inet.or.jp/people/b-monkey.

51. Sur les doro-e, on se référera aux publications suivantes: Edo no doro-e ten. Watanabe Shin.ichirō-shi korekushon 江戸の泥絵展 - 渡辺紳一郎氏コレクションHamamatsu-shi bijutsukan, 1977 (catalogue d'exposition de la collection Watanabe, qui comporte environ 300 pièces) ; Ono Tadashige 小野忠重, Garasu-e to doro-e. Bakumatsu, Meiji no shomin-ga kō ガラス絵と 泥絵一幕末 ・明治庶民画考, Tōkyō, Kawade shobō shinsha, 1990 ; Satō Morihiro 佐藤守弘, «Topogurafia to shite no meisho-e. Edo doro-e to toshi no shikaku bunka »トポグラフィアとし ての名所絵－江戸泥絵と都市の視覚文化, Bigaku geijutsugaku 美学芸術学, $\mathrm{n}^{\circ} 14,1999$; Satō Morihiro 佐藤守弘, «Toshi to sono hyōshō. Shikaku bunka to shite no Edo doro-e » 都市とその 表象一視覚文化としての江戸泥絵, Bigaku 美学, n² 202, 2000.

52. Cf. Edo geijutsu-ron 江戸藝術論, dans Christophe Marquet, op. cit., p. 319-320.

53. Voir l'ouvrage que Kishida Ryūsei 岸田劉生 consacra à ce sujet en 1926 : Shoki nikuhitsu ukiyo$e$ 初期肉筆浮世繪 (Les débuts de la peinture ukiyo-e). Kishida y évoque lui aussi les doro-e, qu'il qualifie de peintures «grossières" (gete no mono 下テのもの), mais pleines de saveur, et il en 
reproduit deux exemples de sa propre collection, attribués au peintre occidentaliste Aōdō Denzen 亜欧堂田善 (1748-1822).

54. Walter Benjamin, L'Euvre d'art à l'époque de sa reproductibilité technique (première version, 1935), traduction de Rainer Rochlitz, in CEuvres III, Paris, Gallimard, 2000, p. 67-113.

55. Yanagi Sōetsu, Zakki no bi, 1927, repris dans Mingei yonjū-nen, Tōkyō, Iwanami shoten, coll. «Iwanami bunko », 1984, p. 95.

56. Voir par exemple les travaux de Kishi Fumikazu 岸文和 sur l'« acte pictural », Kaiga kōi-ron. Ukiyo-e no puragumatikusu 絵画行為論 - 浮世絵のプラグマティクス, Kyōto, Daigo shobō, 2008.

57. Cho Cha-yong, "Yi-Dynasty Painting and the Concept of Folk Art", in Cho Cha-yong, Lee Ufan, Traditional Korean Painting. A Lost Art Rediscoverd, Tōkyō, Kodansha International, 1990, p. 159-173.

58. Yanagita Kunio, Yanagi Sōetsu, Shikiba Ryūzaburō 式場隆三郎, Higa Shunchō 比嘉春潮, 《Mingeigaku to minzokugaku no mondai »民藝學と民俗學の問題 (Études sur les arts populaires et études folkloriques), Gekkan Mingei, vol. 2, no 4, avril 1940, repris dans YSZ, t. 10, 1982, p. 735-747. Voir la traduction de Damien Kunik et Jean-Michel Butel dans ce numéro.

59. Yanagi Sōetsu, «Mingeigaku to minzokugaku»民藝學と民俗學 (Les études sur l'art populaire et les études folkloriques), Kōgei, $\mathrm{n}^{\circ}$ 104, juin 1941, repris dans YSZ, t. 9, 1980, p. 272-287.

60. Yanagi évoque également cette différence d'approche des plaquettes votives dans «Nihon mingeikan »日本民藝館 (La Maison des arts populaires), 1954, repris dans YSZ, t. 16, 1981, p. 190. 61. Dans une lettre à Jean Buhot du 25 décembre 1938, Leroi-Gourhan déclare à propos des Ōtsu$e$ : "J'ai à peu près tous les thèmes maintenant en reproduction ou en originaux et copies tardives. » Dans une lettre du 23 du même mois, il dresse la liste des « images populaires » en sa possession. Cf. André Leroi-Gourhan, Pages oubliées sur le Japon, recueil posthume établi par JeanFrançois Lesbre, Grenoble, Éditions Jérôme Million, 2004, p. 72 et p. 67. Une petite partie des plaquettes votives (22 numéros) et des peintures d'ōtsu (3 numéros) réunies par Leroi-Gourhan se trouve aujourd'hui au Musée du quai Branly (voir site http://www.culture.fr/collections).

62. La rédaction de cet ouvrage, qui prévoyait l'étude de différents genres de peintures et d'objets populaires (plaquettes votives, jouets, peintures d'ōtsu, armoiries, etc.), de leurs formes et de leurs sujets, fut entreprise au début des années 1940, mais elle resta inachevée. Le manuscrit en a été édité par Jean-François Lesbre dans ibid, p. 276-377.

63. André Leroi-Gourhan, Documents pour l'art comparé de l'Eurasie septentrionale, Paris, Les éditions d'art et d'histoire, 1943, p. 88.

64. Leroi-Gourhan cite, dans une lettre à Buhot (op. cit, Pages oubliées sur le Japon, p. 105), le livre Shoki Ōtsu-e de Yanagi, à propos de l'interprétation d'une peinture d'Ōtsu. Il évoque aussi, dans une lettre de mai 1938 (ibid., p. 40), sa visite du «musée paysan de Tokyo ", fondé par Yanagi l'année précédente. Enfin, dans Formes populaires de l'art religieux au Japon, il se réfère à des études japonaises récentes sur les plaquettes votives, dont celle d'Akashi Someto 明石染人 qui les envisage du point de vue de l'«art populaire " (Akashi Someto, "Mingei to shite no ema no kōsatsu » 民藝としての繪馬の考察, Bi 美, vol. 23, nº 4-5, Kyōto, Unsōdō, 1929).

65. Ibid., p. 285.

66. Yanagi Sōetsu, 《Nihon mingei bijutsukan setsuritsu shuisho》日本民藝美術館設立趣意書 (Manifeste pour la création d'un Musée des arts populaires), avril 1926, repris dans YSZ, t.16, 1981, p. 5-10.

67. Dans une conférence à son retour du Japon, Leroi-Gourhan parla de sa rencontre à Kyōto avec Kawai Kanjirō, qui fut son "précieux conseiller d'art populaire» (op.cit., Pages oubliées sur le Japon, p. 412).

68. Lettre à Jean Buhot, 20 mai 1938, ibid., p. 40. 


\section{RÉSUMÉS}

Par la redécouverte d'œuvres picturales populaires japonaises et coréennes antérieures au $\mathrm{xx}^{\mathrm{e}}$ siècle, Yanagi Sōetsu appelle à révolutionner le concept même de peinture pour renouveler la création contemporaine.

After he focused on Pre-Modern Japanese and Korean folk paintings, Yanagi Sōetsu revolutionized the concept of "painting" in order to revitalize contemporary art/creation.

\section{INDEX}

キーワード : kōgei 工芸, minshū geijutsu 民衆芸術, busshitsu bunka 物質文化, taishū bunka 大 衆文化, minzoku 民俗, mingei undō 民芸運動, Mingeikan 民芸館, kankokuga 韓国画, minga 民 画, Yanagi Sōetsu 柳宗悦 (1889-1961), minzokugaku 民族学, bijutsushi 美術史, Taishō jidai 大正 時代 (1912-1923), Shōwa jidai 昭和時代 (1923-1945), Shōwa jidai 昭和時代 (1945-1989)

Thèmes : ethnologie, histoire de l'art

Keywords : Art - History, Ethnology, Folk Art, Folk-crafts, Folklore, Korean Painting, Material Culture, Mingei, Popular Culture

Mots-clés : art paysan, artisanat, arts populaires, culture matérielle, culture populaire, folklore, mingei - mouvement artistique, Musée des arts populaires, peinture coréenne, peinture populaire

Index chronologique : Shōwa (1923-1945), Shōwa (1945-1989) 